\title{
Fiscal Equalization and Lobbying
}

June 15, 2016

\author{
Alejandro Esteller-Moré \\ Facultat d'Economia i Empresa, Universitat de Barcelona, c/ John M. Keynes, 1-11, 08034 \\ Barcelona, Spain \\ Institut d'Economia de Barcelona (IEB), c/ John M. Keynes, 1-11, 08034 Barcelona, Spain \\ e-mail: aesteller@ub.edu \\ Umberto Galmarini (corresponding author) \\ Dipartimento di Diritto, Economia e Culture, Università dell'Insubria, Via S.Abbondio 9, 22100 \\ Como (CO), Italy \\ Institut d'Economia de Barcelona (IEB), c/ John M. Keynes, 1-11, 08034 Barcelona, Spain \\ e-mail: umberto.galmarini@uninsubria.it \\ Leonzio Rizzo \\ Dipartimento di Economia e Management, Università di Ferrara, Via Voltapaletto 11, 44121 \\ Ferrara, Italy \\ Institut d'Economia de Barcelona (IEB), c/ John M. Keynes, 1-11, 08034 Barcelona, Spain \\ e-mail: leonzio.rizzo@unife.it
}

\begin{abstract}
Inter-regional redistribution through tax-base equalization transfers is examined in a setting in which taxpayers, organized as lobby groups, influence policy making. With lobbying only at the local level on tax rates, social welfare maximization implies, ceteris paribus, high (low) equalization rates on the tax bases backed by the strong (weak) lobby groups. With lobbying also at the central level, equalization is distorted downward on all tax bases if the pressure groups are similar in terms of lobbying power. It is instead distorted downward (upward) on the bases backed by strong (weak) groups if they are highly heterogeneous. In the latter situation, a uniform equalization structure may perform better than a differentiated one.
\end{abstract}

Keywords: Fiscal-capacity equalization-transfers; Special interest groups; Inter-regional redistribution; Equity-efficiency trade-off; Uniform versus differentiated equalization.

JEL Classification: H77, D72, H21. 


\section{Introduction}

Fiscal equalization programs represent an important feature of public sector finance in many states with multiple levels of government (Blöchliger and Charbit, 2008; OECD, 2013). Since, generally, the local tax bases and the local public expenditure needs are not uniformly distributed over the territories of the state, fiscal equalization aims at reducing such gaps, thereby limiting the disparities in terms of net fiscal benefits for similar individuals living in different regions. However, the gains in terms of equity stemming from fiscal equalization must be confronted with its costs in terms of efficiency, since the transfer mechanism can distort the local governments' tax and expenditure decisions, as well as the location choices of individuals and firms.

The literature on fiscal equalization can be divided into two main strands. The first examines, at a general level, the assignment of the allocative and distributive functions between the central and the sub-national governments, and the role of intergovernmental transfer programs. This literature can be traced back to the works of Buchanan and Goetz (1972), Flatters et al. (1974), Boadway and Flatters (1982), where emphasis is given to inefficiencies in the allocation of the population as a consequence of fiscal externalities in the presence of perfect mobility of the population. In this setting, the role of transfers is to internalize the fiscal externalities. More recent contributions, e.g. Dahlby (1996), Sato (2000) and Albouy (2012), extend the previous models by assuming imperfect mobility of the population and distortionary taxation. The analysis of the optimal design of grant schemes based on the equalization of the social marginal cost of raising tax revenue across jurisdictions is due to Dahlby and Wilson (1994), while Gordon and Cullen (2011) examine the interplay between redistribution policies at the central and at the local level.

The second strand of the literature is more policy-oriented and examines the functioning of particular forms of fiscal equalization schemes that are used in practice. Among these, the grants aimed at fiscal-capacity equalization receive a great deal of attention, since, as we document in Section 2, programs of this kind are implemented both in federal and unitary states. Fiscal capacity equalization can be based either on standard tax revenues (tax-base equalization) or on actual tax revenues (tax-revenue equalization). While tax-base equalization is usually employed when local governments have ample tax autonomy, including the power to freely set tax rates, tax-revenue equalization is employed when tax autonomy is limited, with tax rates decided at the central level and local governments concurring to tax collection. Focusing on the representative tax system (RTS) equalization scheme for the Canadian Provinces, Smart (1998) offers a clear theoretical analysis of the incentive effects of tax-base equalization, by which 
a local jurisdiction is entitled to a grant that depends on the difference between the national-average and its own per capita standard tax revenues. Since the latter, which depend on the actual tax bases, are a decreasing function of the actual tax rates, the equalization program gives the local governments an incentive to obtain more grants by raising their tax rates. Of the opposite sign are the incentives provided by tax-revenue equalization, since when a local government reduces its fiscal effort, by reducing its own tax revenues it increases the equalization grant, which is based on the gap between average and own actual tax revenues. The empirical works by Esteller-Moré and Solé-Ollé (2002) and Smart (2007) for Canada, and Buettner (2006) for Germany, generally confirm the relevance of the incentives that tax-base equalization gives to set excessively high tax rates at the local level, while Baretti et al. (2002) show that the German interstate transfer system, based on tax revenues, discourages fiscal effort by local governments on tax administration and enforcement.

Following this line of research, some authors have observed that the distorting incentives of fiscal equalization should be confronted with those arising from horizontal tax competition among local governments. The focus of the analysis then becomes that of investigating whether and to what extent the two kinds of distortions reciprocally offset (see, e.g., Köthenbuerger, 2002, and Bucovetsky and Smart, 2006, for theoretical analysis; Rizzo, 2008, also includes an empirical test). If taxation at the local level is inefficiently low because of tax competition, then tax base equalization turns out to be good both for equity, by redistributing from low to high fiscal capacity regions, and for efficiency, by providing incentives to raise local tax rates.

The perspective taken in the above studies is chiefly a normative one, with policy makers behaving as benevolent social welfare maximizers. However, it is well known that actual policy making is also driven by the incentives provided by political institutions. Taking up this point, the main purpose of the present work is to further the understanding of the functioning of fiscal equalization programs by allowing for a more comprehensive view of the motivations of policy makers; namely, one that includes not only the concern for social welfare but also that for political support by special interest groups. Note, however, that although we frame the activities of the special interest groups using the popular political influence approach developed by Bernheim and Whinston (1986a, 1986b), the scope of our results extends to other forms of citizens' influence on fiscal choices (e.g., Brusco et al., 2014), as well as to situations in which public policies are driven by electoral concerns, like in probabilistic voting settings (e.g., Hettich and Winer, 1988, Dixit and Londregan, 1998).

Linking our theoretical analysis to the practice of fiscal equalization, where equalization at uniform rates on an array of fiscal capacity measures is usually observed, 
another purpose of the present work is to compare uniform and differentiated patterns of equalization rates on local fiscal capacity measures, so as to shed light on the reasons why uniformity is the prevalent practice.

We proceed in two steps. Firstly, we let taxpayers, organized as special interest groups, lobby policy makers at the local level with the purpose to gain a more favorable tax treatment, and thus examine, from a normative perspective, how the central government should optimally adjust the equalization program to account for lobbying induced distortions of local fiscal policies. Secondly, we let taxpayers lobby also the policy maker at the central level and thus describe, from a positive perspective, how the equalization policy can be distorted by lobbying. This allows us to finally examine the normative question about whether it is better, in terms of social welfare, to let the central policy maker differentiate the equalization rates on the various fiscal capacity measures, or force her to set uniform rates (by means, say, of a legal provision).

To analyze the above issues, we set up a simple public finance model, in which the local authorities finance their public expenditure by taxing incomes accruing to two types of production factors. The latter, organized as distinct lobby groups, try to influence policy making. We abstract from differences in fiscal needs or service-cost provision at the local level, while we allow for differentiated fiscal capacities, and we consider tax-base equalization transfers, initially of horizontal type, then of vertical type. In order to focus the analysis on the incentives provided by fiscal equalization on local policies influenced by lobbying, we assume that the locally taxed production factors are immobile. However, as we illustrate in an online Appendix, our results are robust to the introduction of tax competition ensuing from factors' mobility.

We find that it is important to account for politically induced distortions, for tax base elasticities, and for fiscal capacities gaps between rich and poor jurisdictions, in the design of fiscal equalization transfers. If lobbying occurs only at the local level by distorting tax setting, while the central policy maker maximizes social welfare, then, ceteris paribus, optimality requires a high (low) equalization rate for the tax base backed by the strong (weak) lobby group. The explanation is simple. Since local governments are on the increasing side of their Laffer curve, tax-base equalization, by fostering tax rates and local tax revenues, increases inter-regional redistribution. However, because of lobbying, taxation is distorted downward for the strong lobby group and upward for the weak one. Hence, equalization of the tax base backed by the weak lobby group is costly in terms of efficiency, since it gives incentives to local governments to raise an already upward-distorted tax rate. On the contrary, equalization of the tax base backed by the strong lobby group is good for efficiency, since it gives incentives to raise a tax rate that is below its optimal level. Hence, while equalization of tax revenues accruing 
from the weak lobby group faces an efficiency-equity trade-off, that on tax revenues accruing from the strong lobby group is beneficial for both equity and efficiency.

As for the other economic factors, we show that the optimal equalization rates are (i) a decreasing function of tax base elasticities, as a high elasticity implies a large excess burden of inter-regional transfers based on the equalization of local tax revenues, and (ii) an increasing function of the fiscal capacity gaps between rich and poor jurisdictions, as a large gap means large benefits ensuing from inter-regional redistribution. These results closely parallel classical findings in optimal tax theory in the context of personal income and commodity taxation.

If taxpayers lobby also at the central level, we find that the central authority is induced to reduce the equalization rates on all tax bases if the lobby groups are similar in terms of lobbying power. If, instead, the two groups are highly heterogeneous in terms of lobbying power, the central policy maker is led to distort downward (upward) the equalization rate on the tax base backed by the strong (weak) lobby group. In the latter situation, uniform equalization, albeit sub-optimal, performs better, in terms of social welfare, than differentiated equalization highly distorted by lobbying.

The equity-efficiency trade-off affecting inter-regional redistribution, as well as some aspects of the political determinants of the transfer policies, have already been examined in the literature on fiscal federalism, but never jointly, as we do in this paper, and with a focus on issues that are different from ours. Lockwood (1999) and Bordignon et al. (2001) analyze redistribution among regions in a setting of asymmetric information in which, because of moral hazard and adverse selection, the optimal equalization transfers are second best. Kotsogiannis and Schwager (2008) examine how fiscal capacity equalization impacts on the accountability of local politicians. The importance of political incentives on the allocation of grants is stressed by a line of empirical research: Dahlberg and Johansson (2002) focus on electoral incentives, while Levitt and Snyder (1995), Larcinese et al. (2006), and Solé-Ollé and Sorribas-Navarro (2008), examine the partisan alignment hypothesis.

The rest of the paper is organized as follows. Section 2 illustrates the relevance of our theoretical analysis for fiscal equalization in practice. Section 3 presents the theoretical framework. Section 4 examines the normative aspects of horizontal equalization when lobbying occurs only at the local level. Section 5 introduces lobbying at the central level of government. Section 6 briefly examines fiscal equalization of vertical type, leaving all technical details to an online Appendix. Section 7 concludes. 


\section{Relation to fiscal equalization in practice}

In a recent study by the OECD (2013, Table 5.2, p. 107), the revenue equalization programs used around the world are classified according to three dimensions.

The first dimension refers to the direction, horizontal or vertical, of the transfers. With horizontal equalization, the local jurisdictions with above-average fiscal capacity directly subsidize those with below-average capacity. Instead, with vertical equalization, the transfers to local jurisdictions are financed by an upper layer of government, which is usually the central one. The second dimension distinguishes between equalization of actual tax revenues collected and equalization of standard tax revenues, as we have already described in Section 1. Finally, the third dimension of classification refers to the rate of equalization of fiscal capacities, which determines the degree of inter-regional redistribution (a 100\% equalization rate corresponds to 'full progressivity'), as well as the intensity of the incentive effects provided by the transfer program on tax setting and administration by local governments. In principle, the equalization rates can be differentiated along two dimensions: with respect to the distance between actual fiscal capacity and its average value, and with respect to the type of tax revenues subjected to equalization (if, as it is common practice, equalization is based on an array of fiscal capacity measures).

Among the sixteen revenue equalization programs classified in the OECD study, seven belong to federal/regional, and nine to unitary, states. With the exception of the German inter-state equalization program, which is of mixed type, all federal states (Australia, Austria, Canada, Italy, Spain, Switzerland) employ vertical equalization, while four unitary states use horizontal equalization (Denmark, Finland, Norway, Sweden) and the others use a vertical scheme (Greece, Poland, Portugal, Turkey, United Kingdom). But for Finland and Poland, unitary states equalize actual tax revenues, whereas the equalization of standard tax revenues is more common in federal countries.

In most schemes the equalization rates are a decreasing function of per capita fiscal capacity, though the observed patterns are highly heterogeneous. In Sweden, for instance, equalization is almost uniform ( $85 \%$ for municipalities above $115 \%$ of average fiscal capacity, $95 \%$ for those below it). In other countries, the rates are highly differentiated: in Canada and Austria, for instance, the equalization rate is zero for jurisdictions with above-average fiscal capacity, while it is positive for jurisdictions with below-average capacity (50-100\% in Canada, $85 \%$ in Austria); in Finland the rate is $40 \%$ for municipalities above $90 \%$ of average fiscal capacity, $100 \%$ for those below it. In

our theoretical analysis, we first consider a horizontal equalization system with rates of equalization that are uniform with respect to per capita fiscal capacity (i.e., a program 

in which only jurisdictions with below-average fiscal capacity cash the equalization transfer (i.e., a scheme that is similar to the one used in Canada).

All countries considered in the OECD study apply instead uniform equalization rates on the various tax revenues subjected to equalization. ${ }^{1}$ And this is where our theoretical analysis can help to judge whether this kind of arrangement is optimal or not. We find that uniform equalization is in general not optimal, provided that the choice of the equalization rates is made by a benevolent decision maker (see Section 4.2, Proposition 1). A differentiated equalization structure is useful if tax setting at the local level is distorted by the influence of special interest groups, ${ }^{2}$ if the tax elasticities of the equalized tax bases are not uniform (e.g., incomes are more elastic than housing property values), or if the geographical dispersion of the various tax bases is not uniform (e.g., income is usually more unequally distributed than consumption). Instead, if not only tax setting at the local level, but also the choice of the equalization rates at the central level, are distorted by lobbying, then our analysis shows that uniform equalization, as observed in practice, can be a better arrangement than differentiated equalization (see Section 5.2, Proposition 3).

\section{The model}

Consider an economy whose public sector is composed of the central government and a large number of small local jurisdictions (e.g., municipalities). There are two types of localities, indexed by $j=1,2$, equal in number, $J>1$ for each type. The small jurisdictions assumption implies that each locality takes as given the national aggregates (average tax rates and tax bases) of the equalization mechanism when setting its own fiscal policy (see Section 4.1).

In both types of localities, a private good is produced by means of a linear technology that uses two types of inputs, labelled $i=a, b$, each one supplied by a different type of agent. All agents of a given type $i$ have identical preferences and endowments; instead, their productivity can be different in the two types of localities. We assume that the localities are inhabited by immobile agents, i.e., by individuals supplying their own production factor only in their locality of residence. We show that our results are

\footnotetext{
${ }^{1}$ The only exception is Canada, where all standard tax revenues are equalized at $100 \%$ for the recipient Provinces (those with below-average fiscal capacity), whereas actual revenues from natural resources are equalized at $50 \%$. The reason is that with full equalization the public authorities of the territories in which the resources are located would have no appropriate incentives for their development.

${ }^{2}$ See Esteller-Moré et al. (2012) for anecdotal evidence of lobbying by the tobacco and oil industries in the US to influence policy choices about excise taxes on the sale of their products.
} 
robust to production factors' mobility in an online Appendix to this article.

In both types of localities, the local government taxes production factors' incomes to provide a public good, which is produced using a technology that transforms one unit of the private good into one unit of the public good. The private good serves also the role of consumption good and that of numeraire good. All markets are perfectly competitive.

\subsection{Factors' supplies}

All agents are endowed with an exogenous amount, normalized to unity, of a good that can be either directly consumed or supplied as a production factor. For a type- $i$ agent resident in a type- $j$ locality, the endowment constraint is $h_{i j}+x_{i j}=1$, where $h_{i j} \geq 0$ is the quantity directly consumed and $x_{i j} \geq 0$ is the quantity supplied for production. Let $p_{i j}$ be the gross market price of production factor $i$ in a type- $j$ locality. Since markets are perfectly competitive, by linearity of the production function, $p_{i j}$ is constant and equal to the (exogenously given) marginal productivity of production factor $i$ in a type- $j$ locality. Gross income, $y_{i j}=p_{i j} x_{i j}$, is taxed at a proportional rate $t_{i j} \in[0,1]$. The individual budget constraint is then equal to $c_{i j}=\left(1-t_{i j}\right) y_{i j}$, where $c_{i j}$ is the consumption good purchased in the market (the output, and numeraire, good, defined above).

Preferences of a type- $i$ agent for consumption bundles $\left(c_{i j}, h_{i j}\right)$ are represented by the utility function:

$$
u^{i}\left(c_{i j}, h_{i j}\right)=c_{i j}+\phi^{i}\left(h_{i j}\right),
$$

where the strictly concave function $\phi^{i}($.$) represents the utility of direct consumption$ of the endowment. Quasi linearity of the utility function (1) implies that all income effects fall on the demand for market consumption. ${ }^{3}$

Taking $t_{i j}$ and $p_{i j}$ as given, the representative type- $i$ individual solves:

$$
\max _{x_{i j}}\left(1-t_{i j}\right) p_{i j} x_{i j}+\phi^{i}\left(1-x_{i j}\right) .
$$

Denote with $\phi_{h}^{i}$ and $\phi_{h h}^{i}$ the first- and the second-order derivatives of $\phi^{i}$, respectively. The equilibrium factor supply, $\tilde{x}_{i j}\left(p_{i j}, t_{i j}\right)$, that solves problem $(2)$ is defined by the first order condition:

$$
\left(1-t_{i j}\right) p_{i j}=\phi_{h}^{i}\left(1-x_{i j}\right)
$$

\footnotetext{
${ }^{3}$ The quasi-linearity assumption is made for analytical convenience and can be relaxed. For some types of production factors, the empirical estimates of the impact of income taxes on their supply find weak income effects (see, e.g., Gruber and Saez, 2002, for the case of labor supply).
} 
To ensure an interior solution, $\tilde{x}_{i j} \in(0,1)$, assume that $\lim _{x_{i j} \rightarrow 1} \phi_{h}^{i}\left(1-x_{i j}\right)=+\infty$, $\phi_{h}^{i}(1)=0$. Factor's supply is increasing in $p_{i j}, \partial \tilde{x}_{i j} / \partial p_{i j}=-\left(1-t_{i j}\right) / \phi_{h h}^{i}\left(\tilde{h}_{i j}\right)>0$, and decreasing in $t_{i j}, \partial \tilde{x}_{i j} / \partial t_{i j}=p_{i j} / \phi_{h h}^{i}\left(\tilde{h}_{i j}\right)<0$. To simplify the analysis, we assume that the elasticity of factors' supply, $\varepsilon_{i}>0$, is constant. Then:

$$
\frac{\partial \tilde{x}_{i j}}{\partial t_{i j}}=-\frac{\tilde{x}_{i j} \varepsilon_{i}}{1-t_{i j}}<0
$$

By inserting the equilibrium quantities into Eq. (1), the indirect utility function of a type- $i$ agent resident in a type- $j$ locality is:

$$
v_{i j}\left(t_{i j}\right)=\left(1-t_{i j}\right) p_{i j} \tilde{x}_{i j}+\phi^{i}\left(1-\tilde{x}_{i j}\right)
$$

where, by applying the envelope theorem, it is:

$$
\frac{\partial v_{i j}}{\partial t_{i j}}=-p_{i j} \tilde{x}_{i j}<0
$$

The supply of production factors modelled above can be interpreted in familiar ways. If the endowment is expressed in units of time, and $x_{i j}$ is labor time, $h_{i j}$ is leisure time, and $p_{i j}$ is the wage rate, then one obtains the standard neoclassical model of labor supply. As another example, consider a two-period framework with an endowment that in the first period can be allocated to consumption, $h_{i j}$, and investment, $x_{i j}$. Let $p_{i j}$ be the second-period return of investment (including the principal). Then, in the absence of second-period bequests, $c_{i j}$ is second-period consumption, and the model can be interpreted as one of capital supply.

Note that, strictly speaking, the use of distortionary income taxes is unjustified in the present setup. Since taxpayers are divided into two distinct, and observable, groups of identical agents, the efficient instrument would be a uniform lump sum tax - if the only objective is public good financing, or a pair of group-specific lump sum taxes if also some degree of between-groups redistribution is deemed as desirable. However, the aim of this paper is not that of justifying the use of second-best distortionary taxes in place of first-best lump sum instruments, which is usually the focus of optimal tax models. Instead, the objective is the analysis of the efficiency and equity properties of transfer programs that are based on the equalization of fiscal capacities of local governments financing their own public services with distortionary taxes; to this end, and to avoid unnecessary analytical complications, we use a simple two-group, identicalagents, setup.

\subsection{Type-1 ('poor') and type-2 ('rich') localities}

In both types of localities, there is an equal mass, $n_{i}>0, i=a, b$, of agents of each type, $n_{a}+n_{b}=1$. The only source of heterogeneity between type- 1 and type- 2 
localities is production factors' productivity. In particular, we assume that both types of production factors are more productive in type-2 localities than in type- 1 .

Assumption 1 Both types of production factors are more productive in type-2 than in type-1 localities. That is, $p_{i 1}<p_{i 2}, i=a, b$.

The obvious implication of this hypothesis, formally characterized in Section 4.2, is that social welfare is higher in type-2 ('rich') than in type-1 ('poor') localities, providing a rationale for inter-regional redistribution by means of a fiscal equalization program.

\subsection{Tax revenues and equalization grants}

Let

$$
\bar{z}_{k j}\left(t_{k j}\right)=n_{k} p_{k j} \tilde{x}_{k j}, \quad \bar{z}_{k}\left(t_{k 1}, t_{k 2}\right)=\frac{1}{2} \sum_{r=1}^{2} \bar{z}_{k r},
$$

be the per capita tax base of production factor $k$ in a type- $j$ jurisdiction, and the national per capita tax base of production factor $k$, respectively.

Let $\mathbf{t}_{j}=\left(t_{a j}, t_{b j}\right), \mathbf{t}=\left(\mathbf{t}_{1}, \mathbf{t}_{2}\right)$. In a type- $j$ jurisdiction, the per capita tax revenues are equal to:

$$
T_{j}\left(\mathbf{t}_{j}\right)=\sum_{k \in\{a, b\}} t_{k j} \bar{z}_{k j}
$$

The per capita equalization grant takes the following form:

$$
E_{j}(\mathbf{t})=\sum_{k \in\{a, b\}} \theta_{k} \bar{t}_{k}\left(\bar{z}_{k}-\bar{z}_{k j}\right)
$$

where:

$$
\bar{t}_{k}\left(t_{k 1}, t_{k 2}\right)=\frac{\sum_{r=1}^{2} t_{k r} \bar{z}_{k r}}{\sum_{r=1}^{2} \bar{z}_{k r}}
$$

is the national average tax rate on production factor $k$ 's income.

The transfer mechanism defined in Eq. (9) is based on the equalization of fiscal capacities, measured by the standard tax bases. The parameters $\boldsymbol{\theta}=\left(\theta_{a}, \theta_{b}\right), \theta_{k} \geq 0$, $k=a, b$, are the equalization rates, expressing the degree of tax-base equalization.

The formula of the equalization scheme shows that, for production factor $k$, given the national per capita tax base, $\bar{z}_{k}$, and the national average tax rate, $\bar{t}_{k}$, the grant to a type- $j$ locality covers the share $\theta_{k}$ of the gap between the standardized national per capita tax revenue, $\bar{t}_{k} \bar{z}_{k}$, and its standardized per capita tax revenue, $\bar{t}_{k} \bar{z}_{k j}$. As 
described in Section 2, this equalization system is of horizontal type, since the transfers cashed by the 'recipient' jurisdictions (those with below-average fiscal capacity) are financed by the 'donor' jurisdictions (those with above-average fiscal capacity), and in the aggregate total transfers sum up to zero. In contrast, the vertical system that we examine in Section 6 is of vertical type, since positive transfers are paid only to jurisdictions with below-average fiscal capacity, with financing by the central government.

The tax-setting incentives provided by the transfer mechanism are clear. From the point of view of a single jurisdiction, an increase in its own tax rate $t_{k j}$ determines, ceteris paribus, an increase in the grant, since the per capita tax base $\bar{z}_{k j}$ is decreasing in $t_{k j}$. That is, the equalization program gives incentives to local governments to expand taxation, an issue clearly exposed by Smart (1998).

Note also that, in principle, the transfers depend not only on the tax rates set by the receiving jurisdiction, but also on those set by all other jurisdictions, since the latter affect the national per capita tax bases, $\bar{z}_{k}$, and the national average tax rates, $\bar{t}_{k}, k=a, b$. However, recall that we are focusing the analysis on a large number of small local jurisdictions of each type. This implies that any single jurisdiction takes the average values $\left(\bar{z}_{k}, \bar{t}_{k}\right)$ as exogenously given when setting its own fiscal policy. That is, any given type- $j$ jurisdiction perceives the impact of a change in its own tax rate $t_{i j}$ on the equalization transfer as being equal to:

$$
\frac{\partial E_{j}}{\partial t_{i j}}=\bar{z}_{i j} \theta_{i}\left(\frac{\bar{t}_{i} \varepsilon_{i}}{1-t_{i j}}\right)
$$

In a type- $j$ jurisdiction, per capita public good supply is equal to its per capita public resources, $T_{j}+E_{j}$. By differentiating Eq. (8), and combining with Eq. (11), we obtain:

$$
\frac{\partial T_{j}}{\partial t_{i j}}+\frac{\partial E_{j}}{\partial t_{i j}}=\bar{z}_{i j}\left(1-\frac{t_{i j}-\theta_{i} \bar{t}_{i}}{1-t_{i j}} \varepsilon_{i}\right)
$$

\subsection{Social welfare}

Welfare of a type- $i$ agent supplying her own production factor in a type- $j$ locality is:

$$
w_{i j}(\mathbf{t})=v_{i j}\left(t_{i j}\right)+\gamma\left[T_{j}\left(\mathbf{t}_{j}\right)+E_{j}(\mathbf{t})\right]
$$

where $v_{i j}$ is the utility of private consumption, defined in Eq. (5), and $\gamma>1$ is the marginal utility of public expenditure, which is assumed to be constant and exogenously given. ${ }^{4}$

\footnotetext{
${ }^{4}$ The analysis can be generalized, albeit at the cost of some analytical complexity, to the case in which the marginal benefits of the public good are a decreasing function of public expenditure.
} 
Using a Utilitarian criteria to aggregate the individual utilities, social welfare in a type- $j$ jurisdiction is defined as:

$$
W_{j}(\mathbf{t})=\sum_{k \in\{a, b\}} n_{k} w_{k j}(\mathbf{t})
$$

\subsection{Taxpayers' lobbying}

We frame taxpayers' lobbying activities within the conventional 'buying influence' approach, originally conceived by Bernheim and Whinston (1986a, 1986b) and then further developed by Grossman and Helpman $(1994,2001)$ and Dixit et al. (1997). In each locality, we setup a perfect-information common-agency game with three players: two principals (the lobbyists, each one representing the interests of one group of taxpayers) and one agent (the local policy maker). Interest groups compete to sway tax policy to their advantage by openly offering legal monetary rewards (in the form, for instance, of campaign contributions) to the policy maker.

Formally, the game presents two stages. In the first, the taxpayers' lobbyists announce to the policy maker a menu of monetary offers which are contingent on fiscal policies. Following acceptance of the offers, in the second stage the policy maker takes her preferred choice under the influence of the incentives provided by lobbyists. The game can be solved backward using the notion of subgame perfection.

Following Dixit et al. (1997), we assume that the contribution function presented by a lobbyist to the policy maker is of the truthful, or compensating, type. A truthful contribution is a continuous function of the policy instruments that is defined along an indifference curve of the lobbyist; hence, a change in a policy instrument determines a change in the contribution offered to the policy maker that reflects one-to-one the impact of the policy change on the lobbyist's welfare. Truthful contributions are a helpful device for solving this class of common agency games, since the set of the best responses of each principal to the contribution functions (not necessarily truthful) of the other principals always contains a truthful contribution schedule (Dixit et al., 1997, Proposition 2). This also implies that there is no need to bother about whether it is worthwhile or not for a group to lobby, since lobbying is always a dominant strategy. Hence, there is no loss of generality in using this type of contribution functions. Moreover, with truthful contributions the equilibrium of the game is often unique, while in general common agency games admit multiple equilibria.

In a type- $j$ locality, the truthful contribution function offered by lobby group $i$ is:

$$
Q_{i j}\left(\mathbf{t} ; \lambda_{i}, \hat{\pi}_{i j}\right)=\lambda_{i} \max \left\{0, n_{i} w_{i j}(\mathbf{t})-\hat{\Pi}_{i j}\right\}
$$


where $\hat{\Pi}_{i j} \geq 0$ is a scalar representing the net payoff of the lobby group. The parameter $\lambda_{i} \in[0,1]$ represents a measure of the effectiveness of group $i$ in its lobbying activity: the group is fully powerful if $\lambda_{i}=1$; it is completely ineffective if $\lambda_{i}=0$. Following the literature quoted above, we do not model how a group organizes its lobbying activity in order to provide its members with the incentives to pursue the common interest and to overcome free riding behavior. We simply assume the existence of a lobbyist for each group of taxpayers, with an exogenously given 'capacity' to influence policy making, as represented by the parameter $\lambda_{i}$. Note also that the absolute and relative lobbying power of groups $a$ and $b$ is the same in both types of localities, since, as assumed in Section 3.2, the only source of heterogeneity between rich and poor localities is factors' productivity.

To ease the presentation of the results, we also assume, without loss of generality, that one of the two groups is always (weakly) more powerful than the other one in lobbying.

Assumption 2 Group a is always less powerful, at most equally powerful, than group $b$ in lobbying. That is, $\lambda_{a} \leq \lambda_{b}$.

The local policy maker cares both for social welfare, defined in Eq. (14), and for political contributions, defined in Eq. (15). Her objective function is assumed to be linearly additive, with uniform weights, in the two components. Ignoring the nonnegativity constraint on the contribution functions, the objective function of the local policy maker in the second stage of the lobby game can be written as: ${ }^{5}$

$$
\Omega_{j}(\mathbf{t})=\sum_{k \in\{a, b\}} n_{k}\left(1+\lambda_{k}\right) w_{k j}(\mathbf{t})
$$

By looking at Eq. (16), we immediately note that political pressures impact on fiscal policy only if groups $a$ and $b$ are not equally effective in lobbying (i.e., if $\lambda_{a} \neq \lambda_{b}$ ), so that the policy maker ends up maximizing a 'distorted' social welfare function. Instead, if the two groups are equally effective in lobbying (i.e., if $\lambda_{a}=\lambda_{b}$ ), then lobbying does not impact on fiscal policy.

\footnotetext{
${ }^{5}$ The lobby game can be solved by first computing the equilibrium in the policy variables at the second stage by maximizing Eq. (16), which ignores the non-negativity constraints on political contributions. The latter can then be checked ex-post, after having computed the equilibrium net payoffs of the lobby groups, $\left(\hat{\Pi}_{a j}^{*}, \hat{\Pi}_{b j}^{*}\right)$, at the first stage of the game. However, in the present work we do not solve for the first stage of the game, since we are not interested in the distributional effects of lobbying due to the monetary transfers from the lobby groups to the policy maker. We focus only on the second stage of the game, where lobbying impacts on fiscal policy in terms of efficiency and inter-regional redistribution.
} 
Note also that the objective function (16) is compatible with a political setting in which tax policy is driven by electoral competition instead of by special interest groups. In particular, an objective function similar to that shown in Eq. (16) can be obtained within a standard probabilistic voting model in which two parties run for election with the aim of maximizing their vote share, with voters of groups $a$ and $b$ ideologically dispersed in favor of one of the two parties. The weight $\lambda_{k}$ then would represent a measure of the 'political clout' of group $k$, as a function of the mass of its swing voters (see Persson and Tabellini, 2000, for a textbook exposition of the probabilistic voting model, and Dixit and Londregan, 1996, for an application to redistributive tax policy).

\section{The design of fiscal equalization}

In this section, we first derive the fiscal policies set by local governments under the influence of taxpayers' lobbying and of equalization transfers, and then characterize the optimal structure of the fiscal equalization program.

\subsection{Equilibrium local fiscal policies}

Consider a type- $j$ jurisdiction. The local policy maker maximizes the objective function defined in Eq. (16) with respect to the own tax rates $\mathbf{t}_{j}$, taking as given the other jurisdictions' tax rates and the average tax rates, and tax bases, at the national level. For a type- $j$ locality, the first order conditions are (we examine the second order conditions at the end of the section):

$$
\frac{\partial \Omega_{j}}{\partial t_{i j}}=-n_{i}\left(1+\lambda_{i}\right) p_{i j} \tilde{x}_{i j}+\gamma\left(\frac{\partial T_{j}}{\partial t_{i j}}+\frac{\partial E_{j}}{\partial t_{i j}}\right) \sum_{k \in\{a, b\}} n_{k}\left(1+\lambda_{k}\right)=0, \quad i=a, b .
$$

Defining $\bar{\lambda}=n_{a} \lambda_{a}+n_{b} \lambda_{b}$, and using Eq. (12), Eq. (17) can be manipulated to obtain:

$$
\frac{t_{i j}-\theta_{i} \bar{t}_{i}}{1-t_{i j}}=\frac{\gamma-\left(1+\lambda_{i}\right) /(1+\bar{\lambda})}{\gamma \varepsilon_{i}}, \quad j=1,2, \quad i=a, b .
$$

In principle, the equilibrium local fiscal policies of the federation are defined by a system of $4 J$ equations in the $4 J$ tax rates set by the $2 J$ jurisdictions. However, since the $J$ jurisdictions of type $j, j=1,2$, are identical, we can focus on the symmetric equilibria in which all jurisdictions of the same type set the same fiscal policy. This reduces the $4 J$-equation system to the four-equation system shown in Eq. (18). Furthermore, note that the r.h.s. of Eq. (18) is independent of jurisdictions' type: this is a consequence of the fact that the lobbying power, $\lambda_{i}$, and the relative size, $n_{i}$, of groups 
$a$ and $b$, are the same in both types of localities. This implies that $t_{i j}$ on the l.h.s. is independent of $j$, which in turn implies that $t_{i 1}=t_{i 2}=\bar{t}_{i}$. That is, type- 1 and type- 2 jurisdictions set the same tax rate on tax base $i$, and therefore the individual tax rates $\left(t_{i 1}, t_{i 2}\right)$ are equal to their average $\bar{t}_{i}$. Hence, each equilibrium tax rate $t_{i}^{*}$ on tax base $i$ is characterized by a single equation, as a function of the lobbying parameters and the equalization rate, as follows:

$$
\frac{t_{i}^{*}}{1-t_{i}^{*}}=\frac{\gamma-\left(1+\lambda_{i}\right) /(1+\bar{\lambda})}{\gamma\left(1-\theta_{i}\right) \varepsilon_{i}}, \quad i=a, b
$$

Recall that, in Section 3.4, we assumed $\gamma>1$. In the absence of lobbying distortions, $\gamma>1$ ensures that, for $\theta_{i} \in[0,1]$, the marginal (and average) tax rate $t_{i}^{*}, i=a, b$, defined in Eq. (19), is strictly positive but not greater than unity (it is $t_{i}^{*}=1$, i.e., $100 \%$, for $\left.\theta_{i}=1\right)$. Instead, under lobbying distortions the tax rate $t_{b}^{*}$ is negative (i.e., a subsidy) if $1<\gamma<\left(1+\lambda_{b}\right) /(1+\bar{\lambda})$. Clearly, we prefer to rule out income subsidization, since equalization of negative tax revenues redistributes in the wrong direction, from poor to rich localities, as well as marginal tax rates above $100 \%$. Hence, we introduce the following restrictions, to ensure that $t_{i}^{*} \in[0,1], i=a, b$.

Assumption $3 \theta_{i} \in[0,1], i=a, b ; \gamma-\left(1+\lambda_{b}\right) /(1+\bar{\lambda}) \geq 0$.

Eqs. (19) highlight the factors driving tax choices. If lobbying is absent or ineffective (i.e., $\lambda_{b}=\lambda_{a}=\bar{\lambda} \geq 0$ ) and fiscal equalization is not present (i.e., $\theta_{i}=0$ ), then local taxation is second-best efficient, since each tax rate $t_{i}$ is set by equating marginal benefits and marginal costs of public expenditure. The latter are an increasing function of the compensated elasticity, $\varepsilon_{i}$, of the tax base, which determines the excess burden of taxation. Hence, the higher the marginal benefits, $\gamma$, and the lower the elasticity of tax base $i, \varepsilon_{i}$, the higher the equilibrium tax rate $t_{i}^{*}$. Fiscal equalization distorts taxation upwards, since $t_{i}^{*}$ is increasing in $\theta_{i}$, the equalization rate of tax base $i$. Finally, if the special interest groups are heterogeneous in terms of lobbying power, that is, $\lambda_{b}>\bar{\lambda}>\lambda_{a}$ (recall Assumption 2), then taxation is distorted downward on group $b$ and upward on group $a$.

Assumption 3 represents also a sufficient condition for the concavity of the objective function of local governments in the own tax rates. In fact, by differentiating the derivative in Eq. (17), we get:

$$
\frac{\partial^{2} \Omega_{j}}{\partial t_{i j}^{2}}=-\gamma(1+\bar{\lambda})\left[1-\frac{1+\lambda_{i}}{\gamma(1+\bar{\lambda})}+\frac{\left(1-t_{i j}+\theta_{i} \bar{t}_{i}\right) \varepsilon_{i}}{1-t_{i j}}\right] \frac{\bar{z}_{i j} \varepsilon_{i}}{1-t_{i j}}, \quad i=a, b .
$$

Assumption 3 is sufficient to ensure that the second order derivatives in Eq. (20) are both negative. Moreover, the Hessian is positive, since $\partial^{2} \Omega_{j} /\left(\partial t_{a} \partial t_{b}\right)=0$. Hence, $\Omega_{j}$ is concave in the tax rates. 
Recall that, by Assumption 1, type-2 localities are more productive than type-1. This implies that, in the absence of central government intervention, the per capita social welfare is higher in type-2 than that in type-1 localities. Fiscal equalization can then be used to redistribute from rich to poor localities.

We assume that the central authority aims at maximizing a Utilitarian nonsymmetric social welfare function of per capita local welfare levels: ${ }^{7}$

$$
\Psi(\boldsymbol{\theta})=W_{1}^{*}(\boldsymbol{\theta})+(1-\psi) W_{2}^{*}(\boldsymbol{\theta}),
$$

where $\psi \in[0,1]$ is a parameter expressing the preferences for inter-regional redistribution. If $\psi=0$, the social welfare function is Utilitarian symmetric, with equal weights for type- 1 and type- 2 localities. If $\psi=1$, the social welfare function is of maximin or Rawlsian type, since the objective is to maximize per capita welfare of poor localities.

\footnotetext{
${ }^{6}$ Social welfare, as defined in Eq. (21), represents a linear aggregation, with uniform weights, of net welfare of resident agents (gross welfare less political contributions paid to the local policy maker), and policy maker's welfare (political contributions). Representing a pure transfer from lobbyists to policy makers, political contributions cancel out from the expression for social welfare.

${ }^{7}$ Although we have assumed that there are $J>1$ identical localities of each type $j, j=1,2$, to ease the notation, and without loss of generality, we compute national aggregates by considering one locality of each type only.
} 
Note that in the Utilitarian symmetric case the social planner is concerned only about efficiency. To see this, recall that (i) the marginal utility of private consumption is constant and uniform for all types of agents in all localities, and (ii) the marginal utility of local public expenditure is also constant and uniform in all localities. Then the national social welfare function (22), for $\psi=0$, shows no preference for redistribution, both at the individual and at the local level; indeed, it is invariant to any kind of balanced-budget lump sum transfers among individuals or localities. It is sensitive only to the efficiency costs of tax distortions. For $\psi>0$, instead, the social planner cares for both efficiency and equity (maximal preference for equity if $\psi=1$ ).

Note also that the objective function (22) is well-behaved for the problem at hand, since fiscal equalization can never determine re-ranking between high and low productivity localities, in terms of per capita fiscal capacity, individual welfare and per capita local welfare. We formalize this property of fiscal equalization in the following lemma, which also establishes that full equalization of fiscal capacities cannot be optimal.

Lemma 1 Assume A.1 (type-2 localities are more productive than type-1) and A.3 (local marginal tax rates are non-negative, and not greater than 100\%, on both production factors' incomes). Then, $\theta_{i}=1$ cannot be optimal. For any equalization rate $\theta_{i} \in[0,1)$, the per capita tax base on production factor $i$, the welfare of type-i agents, and the per capita local social welfare, are strictly higher in type-2 than in type-1 localities. That $i s: \bar{z}_{i 1}^{*}<\bar{z}_{i 2}^{*}, w_{i 1}^{*}<w_{i 2}^{*}, i=a, b ; W_{1}^{*}<W_{2}^{*}$.

Proof. Under A.1 and A.3, with no equalization $\left(\theta_{i}=0\right)$, by Eqs. (19), the equilibrium marginal tax rates are positive and below 100\%; hence, factors supplies, incomes, and social welfare, are positive in both types of localities. With full equalization $\left(\theta_{i}=1\right)$, the marginal tax rates are equal to $100 \%$; hence, factors supplies, incomes, and social welfare, are nil in both types of localities. This shows that $\theta_{i}=1$ cannot be optimal. As for the second part of the lemma, recall that type- 1 and type- 2 localities set identical and positive tax rates $t_{i}^{*}$. Hence, by Assumption $1,\left(1-t_{i}^{*}\right) p_{i 1}<\left(1-t_{i}^{*}\right) p_{i 2}$. Since factors' supplies are upward sloping, the latter inequality implies $p_{i 1} x_{i 1}^{*}<p_{i 2} x_{i 2}^{*}$, $v_{i 1}^{*}<v_{i 2}^{*}$. Moreover, $\bar{z}_{i 1}^{*}<\bar{z}_{i 2}^{*}$, since type- $a$ and type- $b$ agents are in the same proportion in both types of localities. For $\theta_{i}<1, i=a, b$, per capita public expenditure, $T_{j}^{*}+E_{j}^{*}$, is higher in type-2 than in type- 1 localities, since tax revenues are higher while the equalization mechanism does not fully equalize total resources. Higher welfare from private consumption $\left(v_{i 1}^{*}<v_{i 2}^{*}\right)$ and higher benefits from public goods imply that all agents of a given type resident in type-2 localities are better off than those of the same type resident in type- 1 localities. That is, $w_{i 1}^{*}<w_{i 2}^{*}$. This also implies that the per capita social welfare is higher in type- 2 than in type- 1 localities. 
To compute the impact on a type- $j$ locality's social welfare of an increase in fiscal equalization, we differentiate Eq. (21) with respect to $\theta_{i}$, obtaining:

$$
\frac{\partial W_{j}^{*}}{\partial \theta_{i}}=-n_{i} p_{i j} x_{i j}^{*} \frac{\partial t_{i}^{*}}{\partial \theta_{i}}+\gamma\left(\frac{\partial T_{j}^{*}}{\partial \theta_{i}}+\frac{\partial E_{j}^{*}}{\partial \theta_{i}}\right)
$$

Recall that $t_{i j}^{*}=t_{i}^{*}=\bar{t}_{i}^{*}, j=1,2$. Hence, in equilibrium, tax revenues and equalization grants are equal to:

$$
T_{j}^{*}\left(\mathbf{t}^{*}\right)=\sum_{k \in\{a, b\}} t_{k}^{*} \bar{z}_{k j}^{*}, \quad E_{j}^{*}\left(\mathbf{t}^{*}\right)=\sum_{k \in\{a, b\}} \theta_{k} t_{k}^{*}\left(\bar{z}_{k}^{*}-\bar{z}_{k j}^{*}\right)
$$

respectively, with derivatives:

$$
\begin{aligned}
\frac{\partial T_{j}^{*}}{\partial \theta_{i}} & =\bar{z}_{i j}^{*}\left(1-\frac{t_{i}^{*} \varepsilon_{i}}{1-t_{i}^{*}}\right) \frac{\partial t_{i}^{*}}{\partial \theta_{i}}, \\
\frac{\partial E_{j}^{*}}{\partial \theta_{i}} & =t_{i}^{*}\left(\bar{z}_{i}^{*}-\bar{z}_{i j}^{*}\right)+\theta_{i}\left(\bar{z}_{i}^{*}-\bar{z}_{i j}^{*}\right)\left(1-\frac{t_{i}^{*} \varepsilon_{i}}{1-t_{i}^{*}}\right) \frac{\partial t_{i}^{*}}{\partial \theta_{i}} .
\end{aligned}
$$

We use Eqs. (24)-(25) and the fact that, by Eq. (19),

$$
\frac{t_{i}^{*} \varepsilon_{i}}{1-t_{i}^{*}}=\frac{\gamma-\Lambda_{i}}{\gamma\left(1-\theta_{i}\right)}, \quad \Lambda_{i}=\frac{1+\lambda_{i}}{1+\bar{\lambda}}
$$

to manipulate Eq. (23). This allows us to obtain the following expression for the impact of an increase in the equalization rate $\theta_{i}$ on social welfare $(22)$ as:

$$
\begin{aligned}
& \frac{\partial \Psi}{\partial \theta_{i}}=\psi \gamma\left(\bar{z}_{i}^{*}-\bar{z}_{i 1}^{*}\right) t_{i}^{*}+\frac{\psi \theta_{i}\left(\Lambda_{i}-\gamma \theta_{i}\right)}{1-\theta_{i}}\left(\bar{z}_{i}^{*}-\bar{z}_{i 1}^{*}\right) \frac{\partial t_{i}^{*}}{\partial \theta_{i}}+ \\
&+\left(\frac{\Lambda_{i}-1-(\gamma-1) \theta_{i}}{1-\theta_{i}}\right)\left[\bar{z}_{i 1}^{*}+(1-\psi) \bar{z}_{i 2}^{*}\right] \frac{\partial t_{i}^{*}}{\partial \theta_{i}}
\end{aligned}
$$

The derivative in Eq. (26) highlights the key factors driving the design of the fiscal equalization system, by showing that an increase in the equalization rate of tax base $i$ impacts on social welfare through three channels, two of which bear on equity, one on efficiency. The first term in the derivative is a mechanical equity term, since it accounts for the marginal transfer of resources from rich to poor localities of a marginal increase in fiscal equalization, for given levels of local tax revenues. The second term is a behavioral equity term, since it accounts for the impact of a marginal change in the degree of fiscal equalization on local tax revenues. If taxation is on the increasing side of the Laffer curve (a condition that can be seen to hold if $\Lambda_{i}>\gamma \theta_{i}$ ), then an increase in $\theta_{i}$, by increasing the equilibrium tax rate $t_{i}^{*}$, increases tax revenues in both types of localities and also the amount of transfers from rich to poor localities. Under Assumption 1 , it is $\bar{z}_{i}^{*}>\bar{z}_{i 1}^{*}$, hence both equity terms are positive, provided that the social planner has some preference for redistribution, i.e., $\psi>0$. Finally, the third 
Table 1: Optimal equalization in the absence of lobbying.

term in Eq. (26) accounts for the impact of a marginal increase in the equalization rates on efficiency. If local taxation is not distorted by lobbying, i.e., if $\Lambda_{i}=1$, then the term is nil for $\theta_{i}=0$ and negative for $\theta_{i}>0$; the reason is that fiscal equalization, by distorting taxation upwards, is detrimental for efficiency. If, instead, taxation is distorted by lobbying, then $\Lambda_{b}>1$ and $\Lambda_{a}<1$ : since the tax rate $t_{b}^{*}$ is distorted downward whereas $t_{a}^{*}$ is distorted upward, efficiency calls in principle for a positive equalization rate on tax base $b$ and negative one on tax base $a$.

Assuming that the second order conditions hold, and that the solution is unique, the optimal equalization parameters, $\theta_{i}^{*}, i=a, b$, are obtained by solving the respective first order conditions, $\partial \Psi / \partial \theta_{i}=0$, obtained from Eq. (26). In order to gain insights about the factors affecting the structure of the optimal equalization scheme, and with a purely illustrative purpose, we resort to some numerical simulations. ${ }^{8}$

We start by considering, in Table 1, optimal equalization in the absence of lobbying distortions, assuming that the central planner maximizes a Rawlsian social welfare function (i.e., $\psi=1$ ). The table reports, for three model specifications, first the laissez faire situation and then that under optimal equalization. In model specification I.0 there is perfect symmetry between production factors $a$ and $b$ : equal tax base elasticities $\left(\varepsilon_{a}=\varepsilon_{b}\right)$ and equal inter-regional productivity ratios $\left(p_{a 2} / p_{a 1}=p_{b 2} / p_{b 1}\right)$. Hence, the optimal equalization rate is the same, $\theta_{i}^{*}=.51$, on both tax bases. Fiscal equalization increases social welfare in type-1 localities $\left(W_{1}^{*}\right.$, that corresponds to social welfare $\Psi$, for $\psi=1$ ), reduces it in type-2 jurisdictions $\left(W_{2}^{*}\right)$, and since it distorts local tax rates upward from 37 to $54 \%$, it reduces aggregate welfare $\left(W^{*}=W_{1}^{*}+W_{2}^{*}\right)$. That is, fiscal equalization strikes a balance between benefits and costs of inter-regional

\footnotetext{
${ }^{8}$ The specification of the utility function $(1)$ is $\phi^{i}=1-5\left[\varepsilon_{i}\left(1+\varepsilon_{i}\right)\right] x_{i j}^{\left(1+\varepsilon_{i}\right) / \varepsilon_{i}}$, that gives the supply function $\tilde{x}_{i j}=\frac{1}{5}\left[\left(1-t_{i j}\right) p_{i j}\right]^{\varepsilon_{i}}$. Second order conditions for a maximum are satisfied in all numerical computations, and the solution is always unique.
} 

optimal equalization rate is higher on the less elastic tax base than on the more elastic one $\left(\varepsilon_{a}<\varepsilon_{b}, \theta_{a}^{*}>\theta_{b}^{*}\right)$. The obvious reason is that the distortion caused by fiscal equalization on tax setting is lower on an inelastic than on an elastic tax base. Finally, with identical tax base elasticities and heterogeneous productivity ratios, model III.0 shows that the optimal equalization rate is higher on the tax base characterized by the higher inter-regional productivity ratio than on the one characterized by the lower ratio $\left(p_{a 2} / p_{a 1}<p_{b 2} / p_{b 1}, \theta_{a}^{*}<\theta_{b}^{*}\right)$. The reason is that the benefits from inter-regional redistribution are larger where fiscal capacity gaps are larger in relative terms.

The results in Table 1, that we summarize below in Proposition 1, parts (ii) and (iii), recover, in the context of inter-regional equalization transfers, some classical findings of optimal tax theory. To see this, note that the equalization program defined in Eq. (9) amounts to employing a pair of linear income taxes, one for each production factor $k$, to redistribute from rich to poor jurisdictions. For type- $j$ localities, their standard tax revenues, $\bar{t}_{k} \bar{z}_{k j}$, represent taxable income. The equalization rate, $\theta_{k}$, is the (constant) marginal tax rate, while the average standard tax revenues, $\bar{t}_{k} \bar{z}_{k}$, determine, under the balanced budget constraint, a lump sum transfer to all localities, $\theta_{k} \bar{t}_{k} \bar{z}_{k}$, akin to the demogrant of a linear income tax. The higher the equalization rate $\theta_{k}$, the higher the degree of progressivity of the inter-regional transfer mechanism. Optimal redistribution strikes a balance between its costs in terms of efficiency, which are a direct function of the (compensated) elasticity of the equalized tax bases, and its benefits in terms of equity, which are a direct function of the gap in fiscal capacities between rich and poor localities. ${ }^{10}$ The rate differentiation result that emerges from model II.0 in Table 1 recovers also the well-known Ramsey inverse elasticity rule of optimal commodity tax theory, by which efficiency calls for tax rates that are inversely related to tax base elasticity.

We now introduce local lobbying into the picture. If groups $a$ and $b$ are equally powerful in lobbying (i.e., $\lambda_{b}=\lambda_{a}>0$ ), then model I.0 in Table 2 shows that lobbying is irrelevant. The pressure groups simply offset each other in the attempt to lean tax policy to their advantage, and the outcome is identical to that in Table 1 in the absence of lobbying. Lobbying affects local tax setting and the optimality conditions for fiscal

\footnotetext{
${ }^{9}$ For given productivity parameters $\left(p_{k 1}, p_{k 2}\right)$, the relative fiscal capacity gap on tax base $k,\left(\bar{z}_{k 2}-\right.$ $\left.\bar{z}_{k 1}\right) / \bar{z}_{k}$, is an increasing function of its elasticity $\varepsilon_{k}$. Hence, in order to isolate the role of the tax base elasticity in the determination of the optimal equalization rate, in model II.0 the parameters $\left(p_{k 1}, p_{k 2}\right)$ are adjusted such that, for both $\varepsilon_{a}=.2$ and $\varepsilon_{b}=.6$, the relative fiscal capacity gap is the same as in the benchmark model I.0, where $\varepsilon_{a}=\varepsilon_{b}=.4$.

${ }^{10}$ The optimal degree of progressivity of the program is also higher the more pronounced are the preferences of the central policy maker for redistribution, here expressed by the parameter $\psi$.
} 


\begin{tabular}{ccc|cccc|ccc}
\hline Model & $\lambda_{a}$ & $\lambda_{b}$ & $\theta_{a}^{*}$ & $\theta_{b}^{*}$ & $t_{a}^{*}$ & $t_{b}^{*}$ & $W_{1}^{*}$ & $W_{2}^{*}$ & $W^{*}$ \\
\hline I.0 & 0.2 & 0.2 & - & - & .37 & .37 & 1.407 & 1.556 & 2.962 \\
& & & .51 & .51 & .54 & .54 & 1.422 & 1.516 & 2.938 \\
\hline I.1 & 0.2 & 0.4 & - & - & .42 & .30 & 1.405 & 1.554 & 2.959 \\
& & & .43 & .61 & .56 & .52 & 1.422 & 1.516 & 2.938 \\
\hline I.2 & 0.2 & 0.6 & - & - & .46 & .23 & 1.403 & 1.551 & 2.953 \\
& & & .36 & .71 & .57 & .51 & 1.423 & 1.515 & 2.938 \\
\hline I.3 & 0.2 & 1.0 & - & - & .51 & .09 & 1.394 & 1.538 & 2.932 \\
& & & .27 & .90 & .59 & .48 & 1.424 & 1.513 & 2.937 \\
\hline
\end{tabular}

Other parameters: $p_{a 1}=p_{b 1}=1.00, p_{a 2}=p_{b 2}=1.25$,

$\varepsilon_{a}=\varepsilon_{b}=0.4, \psi=1, n_{a}=n_{b}=.5, \gamma=1.3$.

Table 2: Optimal equalization with lobbying at the local level.

equalization only if the pressure groups are heterogeneous in terms of lobbying power. With group $b$ more powerful than $a$, Table 2 shows that local taxation is distorted downward on the former group and upward on the latter. Hence, equalization of tax base $b$ is good for both equity and efficiency, since it transfers resources from rich to poor localities and it provides incentives to local governments to raise taxation on the more powerful lobby group. On the contrary, equalization of tax base $a$ is good for equity but is really bad for efficiency, since it gives further incentives to tax an already overtaxed group. Hence, ceteris paribus, optimal equalization under lobbying distortions calls for differentiated equalization rates: a high equalization rate on the tax base backed by the strong lobby group, a low one on that backed by the weak lobby group. As group $b$ becomes relatively more powerful than group $a$, models I.1, I. 2 and I. 3 of Table 2 show that the equalization rate increases on tax base $b$ from $51 \%$ to $90 \%$, while it decreases on tax base $a$ from $51 \%$ to $27 \% .{ }^{11}$ Note also that, when lobbying distortions are important, like in model I.3, fiscal equalization can do good both for equity, by increasing welfare in the poor localities, and for efficiency, by increasing aggregate welfare at the national level.

The results illustrated above are summarized in the following proposition, which is thus given without proof.

\footnotetext{
${ }^{11}$ It can be optimal not to equalize tax base $a$. The corner solution $\theta_{a}^{*}=0$ occurs if, for a given productivity gap $p_{a 2} / p_{a 1}>1$, the lobby power gap $\lambda_{b} / \lambda_{a}>1$ is above a given threshold; or, conversely, if, for a given lobby power gap, the productivity gap is below a given threshold. In this situation, it is optimal to equalize at a positive rate the actual, rather than the standard, tax revenues, of tax base $a$. On this point, see the working paper version of the present work (Esteller-Moré et al., 2015).
} 
Proposition 1 If there is lobbying at the local level, while the central planner chooses the equalization rates to maximize social welfare, then, ceteris paribus, the optimal equalization rate is higher (i) on the tax base backed by the more powerful lobby group, (ii) on the less elastic tax base, (iii) on the tax base characterized by a relatively higher inter-regional fiscal-capacity gap.

\section{$5 \quad$ Fiscal equalization with lobbying at the central level}

We now shift from a normative to a positive perspective by allowing for lobbying also at the central level of government. In particular, we assume that taxpayers act sequentially: in a first stage, they lobby the central policy maker on the choice of the fiscal equalization rates; in a second stage, they lobby their local policy maker on the choice of the tax rates, given the equalization rates set in the first stage. At both stages, the lobby groups offer truthful contribution functions of the type defined in Section 3.5.

As for the second stage, we have already derived, in Section 4.1, Eq. (19), the equilibrium local tax rates, $t_{i}^{*}\left(\theta_{i}\right), i=a, b$. As for the first stage, we define the truthful contribution function offered by lobby group $i$ resident in a type- $j$ locality by substituting $t_{i}^{*}\left(\theta_{i}\right)$ into Eq. (15), which gives: ${ }^{12}$

$$
Q_{i j}^{*}(\boldsymbol{\theta})=\lambda_{i} n_{i} w_{i j}\left(\mathbf{t}^{*}\right)
$$

By summing over groups $i$ and localities $j$, in the aggregate the contributions presented by lobbyists to the central policy maker, as a function of the equalization rates, are equal to:

$$
Q^{*}(\boldsymbol{\theta})=\sum_{j=1}^{2} \sum_{i \in\{a, b\}} Q_{i j}^{*}(\boldsymbol{\theta})=\sum_{j=1}^{2} Q_{j}^{*}(\boldsymbol{\theta}) .
$$

Note that each local group independently lobbies the central policy maker. In fact, production factors of the same type $i$ but resident in different types of localities have different views about the preferred structure of the fiscal equalization program. Typically, individuals resident in a rich locality lobby for lower equalization, since equalization means higher tax burdens, part of which are transferred to poor localities. Individuals resident in a poor locality, instead, may favor higher equalization, if the inflow of equalization transfers more than compensates for the increase in local tax rates.

\footnotetext{
${ }^{12}$ To derive the policy choices under the influence of lobbying, we ignore, as explained in footnote 5 , the non-negativity constraint on political contributions.
} 
The central policy maker cares both for national welfare, as expressed by the social welfare function defined in Eq. (22), and for political contributions by the lobby groups, defined in Eq. (28), with equal weights for the two components. That is, the objective function of the central policy maker is:

$$
\Omega(\boldsymbol{\theta})=\Psi(\boldsymbol{\theta})+Q^{*}(\boldsymbol{\theta})
$$

The first term on the r.h.s. of Eq. (29) is the objective function of the benevolent social planner examined in Section 4.2. The first order condition for maximizing $\Psi(\boldsymbol{\theta})$ is based on the partial derivative shown in Eq. (26). Hence, in order to asses the implications of lobbying at the central level, all we need to do is to characterize the incentives provided by the contribution functions $Q^{*}(\boldsymbol{\theta})$ appearing in Eq. (29).

\subsection{Differentiated equalization rates}

By differentiating $Q_{j}^{*}(\boldsymbol{\theta})$, defined in Eq. (28), with respect to $\theta_{i}$, we get:

$$
\frac{\partial Q_{j}^{*}}{\partial \theta_{i}}=-\lambda_{i} \bar{z}_{k j}^{*} \frac{\partial t_{i}^{*}}{\partial \theta_{i}}+\bar{\lambda} \gamma\left(\frac{\partial T_{j}^{*}}{\partial \theta_{i}}+\frac{\partial E_{j}^{*}}{\partial \theta_{i}}\right) .
$$

Using Eq. (12), the above derivative can be written as:

$$
\frac{\partial Q_{j}^{*}}{\partial \theta_{i}}=\left(\bar{z}_{i}^{*}-\bar{z}_{i j}^{*}\right) \bar{\lambda}\left[\gamma t_{i}^{*}+\frac{\theta_{i}\left(\Lambda_{i}-\gamma \theta_{i}\right)}{1-\theta_{i}} \frac{\partial t_{i}^{*}}{\partial \theta_{i}}\right]+\bar{z}_{i j}^{*}\left(\bar{\lambda} \frac{\Lambda_{i}-\gamma \theta_{i}}{1-\theta_{i}}-\lambda_{i}\right) \frac{\partial t_{i}^{*}}{\partial \theta_{i}} .
$$

By aggregating over $j$, the first term cancels out, while, after some manipulations, the second term can be written as:

$$
\sum_{j=1}^{2} \frac{\partial Q_{j}^{*}}{\partial \theta_{i}}=2 \bar{z}_{i}^{*}\left(\frac{\bar{\lambda}-\lambda_{i}}{(1+\bar{\lambda})\left(1-\theta_{i}\right)}-\frac{\bar{\lambda}\left(\gamma-\lambda_{i} / \bar{\lambda}\right) \theta_{i}}{1-\theta_{i}}\right) \frac{\partial t_{i}^{*}}{\partial \theta_{i}} .
$$

The derivative (30) of the contribution functions shows that the distortions caused by lobbying at the central level on the determination of the equalization rates can be decomposed into two terms. The first one depends on the relative lobbying power of the two groups. By Assumption 2, it is negative for group $b$ and positive for $a$; that is, the more powerful group $b$ induces the central policy maker to lower equalization, and therefore taxation, on its income, at the expense of the less powerful group $a$, whose equalization rate, and hence taxation, increases. The second term calls instead for lower equalization rates on both tax bases, since, by Assumption 3, it is negative for $i=a, b$. Lobbying at the central level, by distorting the preferences of the central policy maker in favor of a more efficient equalization policy, reduces inter-regional redistribution. Note also that the efficiency term is, in absolute value, greater for tax base $a$ than for 


\begin{tabular}{cccc|cccc|ccc}
\hline Model & $\lambda_{a}$ & $\lambda_{b}$ & Lobbying & $\theta_{a}^{*}$ & $\theta_{b}^{*}$ & $t_{a}^{*}$ & $t_{b}^{*}$ & $W_{1}^{*}$ & $W_{2}^{*}$ & $W^{*}$ \\
\hline I.0 & 0.2 & 0.2 & only local & .51 & .51 & .54 & .54 & 1.422 & 1.516 & 2.938 \\
& & & local and central & .43 & .43 & .50 & .50 & 1.421 & 1.527 & 2.948 \\
\hline I.1 & 0.2 & \multirow{2}{*}{0.4} & only local & .43 & .61 & .56 & .52 & 1.422 & 1.516 & 2.938 \\
& & & local and central & .42 & .36 & .55 & .40 & 1.418 & 1.529 & 2.948 \\
\hline I.2 & 0.2 & \multirow{2}{*}{0.6} & only local & .36 & .71 & .57 & .51 & 1.423 & 1.515 & 2.938 \\
& & & local and central & .40 & .26 & .59 & .29 & 1.412 & 1.529 & 2.941 \\
\hline I.3 & 0.2 & \multirow{2}{*}{1.0} & only local & .27 & .90 & .59 & .48 & 1.424 & 1.513 & 2.937 \\
& & & local and central & .37 & .00 & .63 & .09 & 1.395 & 1.517 & 2.912 \\
\hline
\end{tabular}

Other parameters: $p_{a 1}=p_{b 1}=1.00, p_{a 2}=p_{b 2}=1.25$,

$\varepsilon_{a}=\varepsilon_{b}=0.4, \psi=1, n_{a}=n_{b}=.5, \gamma=1.3$.

Table 3: Equalization with lobbying at the local and central level.

tax base $b$, since taxation on the former group is distorted upward by lobbying at the local level, whereas that on the latter group is distorted downward.

The numerical simulations reported in Table 3 confirm the intuitions developed above. With equally powerful lobby groups (model I.0), lobbying at the central level reduces the equalization rates from 51\% (the optimal values, given the Rawlsian objective) to $43 \%$. Hence, while two equally powerful lobby groups do not succeed in distorting policy choices at the local level, they do succeed at the central level. The reason is the one noted above: with equally powerful groups, the truthful contribution functions (28) offered at the central level by the lobby groups amount to a symmetric Utilitarian social welfare function, which provides incentives for a more efficiencyoriented equalization policy (indeed, in the absence of lobbying, the maximization of a symmetric social welfare function implies no equalization). Model I.1 in Table 3 shows that lobbying at the central level reduces both equalization rates, with respect to their optimal values, also when the lobby groups are similar in terms of lobbying power, with an impact that is more pronounced for the more powerful group. If, instead, the groups are highly heterogeneous in terms of lobbying power, then the central policy maker is led to deviate substantially from the optimal policy. As shown by models I.2 and I.3, equalization is lowered on the tax base backed by the more powerful group $b$, and increased on that backed by the less powerful group $a$. In terms of Eq. (30), it means that for group $a$ the (positive) lobby power term exceeds the (negative) lobby efficiency term.

We summarize the above results in the following proposition.

Proposition 2 If taxpayers lobby at both levels of government, both equalization rates 

power. If, instead, the groups are highly heterogeneous in terms of lobbying power, then the equalization rate on the tax base backed by the more powerful group is distorted downward, while that on the tax base backed by less powerful group is distorted upward.

\subsection{Differentiated versus uniform equalization rates}

The normative analysis conducted in Section 4.2 has shown that the optimal rates of fiscal equalization are contingent on the elasticities of the local tax bases subjected to equalization, on the differences in local fiscal capacities, and on the distortions induced by taxpayers' lobbying on local policies. This implies that, in general, the optimal structure of the equalization rates on the various fiscal capacities measures is a differentiated one. However, as we have described in Section 2, in practice what is observed is a pattern of uniform equalization rates. This is apparently a sub-optimal arrangement, since the typical tax bases subjected to equalization are highly heterogeneous in terms of tax rate elasticity, geographical dispersion, political activism of affected taxpayers. However, our theoretical analysis offers also a justification for uniformity of equalization rates, which is prompted by the positive analysis of the impact of lobbying at the central level. The argument is simple. If the choice of the equalization rates at the central level are highly distorted by the pressure of special interest groups, then uniform equalization can perform better than a differentiated one. ${ }^{13}$

Table 4 illustrates with reference to type 2 and type 3 numerical simulations, in which the lobby groups are highly heterogeneous in terms of lobbying power. In models I. 2 and I.3, in which the optimal structure of fiscal equalization is uniform at $51 \%$ (see model I.0 in Table 1), if rate differentiation is allowed, then lobbying at the central level causes an ample differentiation in favor of the more powerful group (40\% and $26 \%$ in model I.2; $37 \%$ and $0 \%$ in model I.3). By setting uniform equalization rates (37\% in model I.2, 34\% in model I.3), the outcome still falls short of the optimal one. However, social welfare in type-1 poor localities is higher under uniform than under differentiated equalization.

Uniform equalization performs better than differential equalization also in type II model, in which the optimal structure of equalization is a differential one, since tax base $a$ is less elastic than $b$. In this case, the benefits of uniformity, that counteract lobbying distortions at the central level, exceed the costs of imposing uniform equalization on tax bases with different elasticities. Clearly, also the opposite outcome is possible, if we

\footnotetext{
${ }^{13}$ We do not model how uniformity of the equalization rates can be imposed; if, for instance, by a legal provision or by a superior constitutional rule. We simply consider the impact of the restriction on social welfare.
} 


\begin{tabular}{cccc|cccc|ccc}
\hline Model & $\lambda_{a}$ & $\lambda_{b}$ & Equalization & $\theta_{a}^{*}$ & $\theta_{b}^{*}$ & $t_{a}^{*}$ & $t_{b}^{*}$ & $W_{1}^{*}$ & $W_{2}^{*}$ & $W^{*}$ \\
\hline I.2 & 0.2 & 0.6 & differential & .40 & .26 & .59 & .29 & 1.412 & 1.529 & 2.941 \\
& & & uniform & .37 & .37 & .57 & .32 & 1.415 & 1.530 & 2.945 \\
\hline I.3 & 0.2 & 1.0 & differential & .37 & .00 & .63 & .09 & 1.395 & 1.517 & 2.912 \\
& & & uniform & .34 & .34 & .62 & .13 & 1.400 & 1.520 & 2.920 \\
\hline II.2 & 0.2 & 0.6 & differential & .47 & .21 & .76 & .20 & 1.475 & 1.590 & 3.065 \\
& & & uniform & .44 & .44 & .75 & .26 & 1.478 & 1.592 & 3.070 \\
\hline II.3 & 0.2 & \multirow{2}{*}{1.0} & differential & .43 & .00 & .79 & .06 & 1.463 & 1.582 & 3.044 \\
& & & uniform & .42 & .42 & .78 & .10 & 1.466 & 1.584 & 3.050 \\
\hline III.2 & 0.2 & 0.6 & differential & .40 & .50 & .59 & .38 & 1.429 & 1.594 & 3.023 \\
& & & uniform & .44 & .44 & .60 & .35 & 1.425 & 1.595 & 3.020 \\
\hline III.3 & 0.2 & 1.0 & differential & .37 & .40 & .63 & .14 & 1.405 & 1.592 & 2.998 \\
& & & uniform & .37 & .37 & .63 & .13 & 1.404 & 1.593 & 2.996 \\
\hline
\end{tabular}

Parameters $p_{a 1}, p_{a 2}, p_{b 1}, p_{b 2}, \varepsilon_{a}, \varepsilon_{b}$, as in Models I, II, III, Table 1.

Other parameters: $\psi=1, n_{a}=n_{b}=.5, \gamma=1.3$.

Table 4: Lobbying at the central level: the benefits of uniform equalization.

consider higher heterogeneity in tax base elasticities. In type III model, in which rate differentiation is motivated by heterogeneity in tax base differentials between type-1 and type-2 localities, uniform equalization is worse than differentiated equalization. However, it is sufficient to decrease the productivity gaps between poor and rich jurisdictions to find examples in which uniform equalization is superior to differentiated equalization.

We generalize the results in the following proposition.

Proposition 3 If taxpayers lobby at both levels of government, and if the lobby groups are sufficiently heterogeneous in terms of lobbying power, then uniform equalization performs better, in terms of social welfare, than differentiated equalization.

The comparison between uniform and non-uniform policies in the presence of lobbying distortions is also examined by Panagariya and Rodrik (1993) with reference to tariffs policy. In their model, the advantage of a uniform tariff over a set of differentiated tariffs is that of moderating lobbying activity. With differentiated tariffs, each pressure group internalizes the private benefits (in terms of a lower tariff on its specific importable production input) and the private costs (in terms of effort to influence the policy maker) of lobbying activity. Instead, with a uniform tariff the benefits are public, giving rise to free riding behavior that reduces aggregate lobbying effort. In our setup, 
a different mechanism is at work, since free riding among lobby groups is not an issue in common agency models of lobbying. Namely, lobbying distorts the preferences of the central policy maker in favor of the more capable pressure group, with the result that one equalization rate is pushed above, while the other one is pushed below, its optimal level; hence, a uniform equalization rate, albeit sub-optimal, may perform better than differentiated equalization.

We finally note that lobbying is not the only source of policy distortion that, in the present context, can point in favor of a uniform policy. ${ }^{14}$ One of such factors is imperfect knowledge, on the part of the central government, of the economic environment at the local level. To illustrate, suppose that the central authority determines the equalization rates using biased estimates of local tax base elasticities (similar results come forth if the central planner uses biased measures of local fiscal capacities). Then, a case in favor of uniformity emerges if the elasticity of the more elastic tax base is overestimated while that of the less elastic tax base is under-estimated, since this causes the equalization rate on the more (less) elastic tax base to be below (above) its optimal level. Clearly, the case for uniformity is weak or absent if both elasticities are overor under-estimated, or if the elasticity of the more elastic tax base is under-estimated while that of the less elastic tax base is over-estimated. Policy distortions can also ensue from the central government favoring politically aligned local jurisdictions. However, in this case uniform equalization is unlikely to outperform differentiated equalization. To see this, suppose that the fraction of 'rich' jurisdictions that are politically aligned with the central government is greater than that of 'poor' jurisdictions, so that the preferences of the central government are biased against egalitarian policies. Because of this bias, both equalization rates are pushed below their optimal levels, which implies that imposing uniformity is unlikely to bring some benefits over differentiation. The result is similar if the central government has a bias in favor of poor localities, since both equalization rates are set above their optimal levels. Contrary to lobbying, that by distorting the equalization rates in opposite directions makes uniformity attractive, regional favoritism on the part of the central government, by distorting the equalization rates in the same direction, makes uniformity useless.

\section{Vertical equalization}

The analysis in the previous sections is framed in the context of an equalization system of horizontal type, in which transfers to poor jurisdictions are financed by rich

\footnotetext{
${ }^{14}$ We thank one referee for urging us to consider these issues. The results, obtained by means of numerical simulations, are available upon request.
} 
jurisdictions of the same layer of government. As illustrated in Section 2, the practice of equalization transfers also employs mechanisms of vertical type, in which it is a higher government layer (usually, the central government) that finances the redistributive program. In this section, we briefly consider vertical equalization, leaving all technical details to an online Appendix.

For the sake of concreteness, we adapt our theoretical framework to fit the Canadian Representative Tax System (RTS) described in Section 2, which is characterized by the fact that transfers are paid only to provinces with below-average fiscal capacity, with financing by the federal government. Thus, we let only the type- 1 poor localities qualify for the transfer, and let the transfers be financed by tax resources at the central level. As for the latter, we do not explicitly model a tax base for the central government, but we simply assume that tax revenues raised at the central level imply an excess burden that, at the margin, is constant and exogenously given.

Horizontal and vertical equalization bear different implications for local tax setting. While under the horizontal scheme examined in the previous sections both types of jurisdictions set the same tax rate on the same type of tax base, under vertical equalization type- 1 localities set tax rates that are higher than those of type- 2 localities, for the simple reason that for the former tax setting is distorted upward by the incentives of equalization, whereas for the latter there are no distortions, as they do not directly participate to fiscal equalization; they participate only indirectly, by contributing to the central tax revenues that finance the program. In formal terms, the tax-setting condition for type- 1 localities is Eq. (18) with $\theta_{i} \geq 0$; for type-2 localities it is Eq. (18) with $\theta_{i}=0$. Hence, for $\theta_{i}>0$, it is $t_{i 1}^{*}>\bar{t}_{i}^{*}>t_{i 2}^{*}$, where $\bar{t}_{i}^{*}$ is the average or standard tax rate defined in Eq. (10). Only $t_{i 1}^{*}$ and $\bar{t}_{i}^{*}$ are an increasing function of $\theta_{i}$.

With lobbying only at the local level, the central planner maximizes the social welfare function (22), with local welfare levels that are now defined as:

$$
\begin{aligned}
& W_{1}^{*}(\boldsymbol{\theta})=\sum_{k \in\{a, b\}} n_{k}\left\{v_{k 1}\left(t_{k 1}^{*}\right)+\gamma\left[T_{1}\left(\mathbf{t}_{1}^{*}\right)+E_{1}\left(\mathbf{t}^{*}\right)\right]\right\}-\xi \delta_{1} E_{1}\left(\mathbf{t}^{*}\right), \\
& W_{2}^{*}(\boldsymbol{\theta})=\sum_{k \in\{a, b\}} n_{k}\left\{v_{k 2}\left(t_{k 2}^{*}\right)+\gamma T_{2}\left(\mathbf{t}_{2}^{*}\right)\right\}-\xi \delta_{2} E_{1}\left(\mathbf{t}^{*}\right),
\end{aligned}
$$

where $\mathbf{t}_{j}^{*}$ is the vector of the equilibrium tax rates in a type- $j$ locality, $\mathbf{t}^{*}=\left(\mathbf{t}_{1}^{*}, \mathbf{t}_{2}^{*}\right)$. The equalization payment is given only to type- 1 jurisdictions, but both types of localities participate to its financing through central taxation. The parameter $\xi>1$ represents the marginal cost of public funds, which is greater than unity because we assume that central taxes are distortionary. The parameters $\delta_{j}, j=1,2, \delta_{1}+\delta_{2}=1$, represent the share of central tax revenues collected in a type- $j$ locality. In this respect, it is natural 
to extend Assumption 1 by assuming that $\delta_{1}<\delta_{2}$ : type- 2 rich localities contribute more than type-1 poor localities.

The formal derivation of the first order conditions that define the optimal structure of the vertical equalization rates with lobbying at the local level is in the online Appendix, which also includes numerical simulations. Here we recap the main findings.

The optimal equalization rates are generally higher under vertical than under horizontal equalization, since, as noted above, vertical equalization is less distortionary than horizontal equalization on local tax setting. As with horizontal equalization, the equalization rates should be adjusted to counteract the distortions caused by lobbying on local tax setting, since it is good for efficiency to use the incentive effects of fiscal equalization to raise taxation on the strong lobby group and to decrease it on the weak one.

With lobbying at both levels of government, under vertical equalization there are no distortions of the equalization rates due to heterogeneity in lobbying power by the two groups (in contrast, with horizontal equalization, heterogeneity matters also for lobbying at the central level). Only the average power of the lobby groups matters. That is, lobbying at the central level distorts the choices of the central policy maker towards a less egalitarian, hence more efficiency oriented, equalization policy.

\section{Concluding remarks}

We have examined the functioning of tax-base equalization transfers in a setting in which taxpayers try to influence policy making both at the local and at the central level of government. Our theoretical analysis helps to assess the practice, adopted by all countries implementing fiscal equalization, of using uniform equalization rates on the various fiscal capacity measures subjected to equalization. If the pressure groups play a negligible role in local tax setting and in redistributive policy, then uniform equalization is in general suboptimal, since it is helpful to differentiate the equalization rates in relation to tax base elasticities and to the degree of their geographical dispersion. If, instead, the lobby groups play an important role, thus severely distorting fiscal equalization, then uniformity of the equalization rates is a better arrangement in terms of social welfare.

In future work, the scope of the analysis can be extended in various directions. First, we can remove the hypothesis of perfect substitutability between production factors. With imperfect substitutability, taxation would bear general equilibrium effects on the before-tax market returns of production factors, thus determining tax shifting between sectors. Second, fiscal equalization can be generalized to include not only 
fiscal capacities but also expenditure needs. Finally, we can consider lobbying by local authorities on the central government to obtain more generous transfers.

Acknowledgements: We thank the Editor, Andreas Haufler, and an anonymous referee for insightful comments. Previous versions of this paper circulated under the title "Fiscal-capacity equalization-grants with taxpayers lobbying" and were presented at the 68th IIPF Congress, Dresden, August 16-19, 2012, at the V Workshop on Fiscal Federalism, IEB, Barcelona, June 13-14, 2013, at the PET Conference, Lisbon, July 5-7, 2013. We thank Lisa Grazzini and seminar participants for useful comments. The authors gratefully acknowledge funding from ECO2015-63591R (MINECO/FEDER, UE).

\section{References}

Albouy, D. (2012). Evaluating the efficiency and equity of federal fiscal equalization. Journal of Public Economics, 96, 824-839.

Baretti, C., Huber, B., \& Lichtblau, K. (2002). A tax on tax revenue: The incentive effects of equalizing transfers: Evidence from Germany. International Tax and Public Finance, 9, 631649.

Bernheim, B.D., \& Whinston, M.D. (1986a). Common agency. Econometrica, 54, 923-942.

Bernheim, B.D., \& Whinston, M.D. (1986b). Menu actions, resource allocation, and economic influence. Quarterly Journal of Economics, 101, 1-31.

Blöchliger, H., \& Charbit, C. (2008). Fiscal equalisation. OECD Economic Studies No. 44, 2008/1. Boadway, R. (2006). Intergovernmental redistributive transfers: efficiency and equity. In Ahmad, E., \& Brosio, G., Handbook of Fiscal Federalism. Edward Elgar.

Boadway, R., \& Flatters, F. (1982). Efficiency and equalization payments in a central system of government: a synthesis and extension of recent results. Canadian Journal of Economics, 15, 613-633.

Bordignon, M., Manasse, P., \& Tabellini, G. (2001). Optimal regional redistribution under asymmetric information. American Economic Review, 91, 709-723.

Brusco, S., Colombo, L., \& Galmarini, U. (2014). Tax differentiation, lobbying, and welfare. Social Choice and Welfare, 42, 977-1006.

Buchanan, J., \& Goetz, C. (1972). Efficiency limits of fiscal mobility: an assessment of the Tiebout model. Journal of Public Economics, 1, 25-43.

Bucovetsky, S., \& Smart, M. (2006). The efficiency consequences of local revenue equalization: tax competition and tax distortions. Journal of Public Economic Theory, 8, 119-144.

Buettner T. (2006). The incentive effect of fiscal equalization transfers on tax policy. Journal of Public Economics, 90, 477-497.

Dahlberg M., \& Johansson, E. (2002). On the vote-purchasing behavior of incumbent governments. American Political Science Review, 96, 27-47. 
Dahlby, B. (1996). Fiscal externalities and the design of intergovernmental grants. International Tax and Public Finance, 3, 397-412.

Dahlby, B., \& Wilson, L.S. (1994). Fiscal capacity, tax effort, and optimal equalization grants. Canadian Journal of Economics, 27, 657-672.

Dixit, A., Grossman, G.M., \& Helpman, E. (1997). Common agency and coordination: general theory and application to government policy making. Journal of Political Economy, 105, 752769.

Dixit, A., \& Londregan, J. (1996). The determinants of success of special interests in redistributive politics. The Journal of Politics, 58, 1132-1155.

Dixit, A., \& Londregan, J. (1998). Ideology, tactics, and efficiency in redistributive politics. Quarterly Journal of Economics, 113, 497-529.

Esteller-Moré, A., Galmarini, U., \& Rizzo, L. (2012). Vertical tax competition and consumption externalities in a federation with lobbying. Journal of Public Economics, 96, 295-305.

Esteller-Moré, A., Galmarini, U., \& Rizzo, L. (2015). Fiscal equalization under political pressures. Document de treball de l'IEB, 2015/21.

Esteller-Moré, A., \& Solé-Ollé, A. (2002). Tax setting in a federal system: The case of personal income taxation in Canada. International Tax and Public Finance, 9, 235-257.

Flatters, F., Henderson, V., \& Mieszkowski, P. (1974). Public goods, efficiency, and regional fiscal equalization. Journal of Public Economics, 3, 99-112.

Gordon, R.H., \& Cullen, J.B. (2011). Income redistribution in a Federal system of governments. Journal of Public Economics, 96, 1100-1109.

Grossman, G.M., \& Helpman, E. (1994). Protection for sale. American Economic Review, 84, 833850.

Grossman, G.M., \& Helpman, E. (2001). Special interest politics. The MIT Press, Cambridge, MA.

Gruber, J., \& Saez, E. (2002). The elasticity of taxable income: evidence and implications. Journal of Public Economics, 84, 1-32.

Hettich, W., \& Winer, S.L. (1988). Economic and political foundations of tax structure. American Economic Review, 78, 701-712.

Köthenbuerger, M. (2002). Tax competition and fiscal equalization. International Tax and Public Finance, 9, 391-408.

Kotsogiannis, C., \& Schwager, R. (2008). Accountability and fiscal equalization. Journal of Public Economics, 92, 2336-2349.

Larcinese, V., Rizzo, L., \& Testa, C. (2006). Allocating the U.S. Federal budget to the States: The impact of the President. The Journal of Politics, 68, 447-456.

Levitt S., \& Snyder, J. (1995). Political parties and the distribution of federal outlays. American Journal of Political Science, 39, 958-980.

Lockwood, B. (1999). Inter-regional insurance. Journal of Public Economics, 72, 1-37.

OECD (2013). Fiscal Federalism 2014: Making Decentralisation Work. OECD Publishing.

Panagariya, A., \& Rodrik, D. (1993). Political-economy arguments for a uniform tariff. International Economic Review, 34, 685-703.

Persson, T., \& Tabellini, G. (2000). Political economics: explaining economic policy. MIT Press. 
Rizzo, L. (2008). Local government responsiveness to federal transfers: theory and evidence. International Tax and Public Finance, 15, 316-337.

Sato, M. (2000). Fiscal externalities and efficient transfers in a federation. International Tax and Public Finance, 7, 119-139.

Smart, M. (1998). Taxation and deadweight loss in a system of intergovernmental transfers. Canadian Journal of Economics, 31, 189-206.

Smart, M. (2007). Raising taxes through equalization. Canadian Journal of Economics, 40, 11881212.

Solé-Ollé, A., \& Sorribas-Navarro, P. (2008). The effects of partisan alignment on the allocation of intergovernmental transfers. Differences-in-differences estimates for Spain. Journal of Public Economics, 92, 2302-2319. 


\section{Online Appendix to the article Fiscal Equalization and Lobbying}

Alejandro Esteller-Moré, Umberto Galmarini, Leonzio Rizzo

June 10, 2016

Section A contains the analytics and the numerical simulations of the vertical equalization scheme considered in Section 6 of the article. Section B extends the analysis of the horizontal equalization program considered in Sections 3-5 of the article by introducing mobility of production factors across local jurisdictions.

\section{A. Vertical equalization}

Under the equalization scheme described in Section 6 of the article, the transfer to a type-1 jurisdiction is equal to:

$$
E_{1}(\mathbf{t})=\sum_{k \in\{a, b\}} \theta_{k} \bar{t}_{k}\left(\bar{z}_{k}-\bar{z}_{k 1}\right)
$$

where $\bar{t}_{k}$ is the average tax rate defined in Eq. (10). The transfer is zero for type-2 jurisdictions.

Gross of the cost of central taxes levied to finance the equalization program, individual welfare levels for type- $i$ agents in type- 1 and type- 2 localities are equal to:

$$
\begin{aligned}
& w_{i 1}\left(\mathbf{t}_{1}\right)=v_{i 1}\left(t_{i 1}\right)+\gamma\left[T_{1}\left(\mathbf{t}_{1}\right)+E_{1}(\mathbf{t})\right], \\
& w_{i 2}\left(\mathbf{t}_{2}\right)=v_{i 2}\left(t_{i 2}\right)+\gamma T_{2}\left(\mathbf{t}_{2}\right) .
\end{aligned}
$$

Under the influence of lobbying, the objective function of the policy maker of a type- $j$ locality is (the local policy maker ignores, and takes as given, centrally raised taxes; hence the latter do not appear in her objective function):

$$
\Omega_{j}\left(\mathbf{t}_{j}\right)=\sum_{k \in\{a, b\}} n_{k}\left(1+\lambda_{k}\right) w_{k j}\left(\mathbf{t}_{j}\right) .
$$

By maximizing the objective function (A.3) for $j=1,2$, we obtain the conditions defining the equilibrium tax rates as:

$$
\begin{aligned}
& \frac{t_{i 2}^{*}}{1-t_{i 2}^{*}}=\frac{\gamma-\left(1+\lambda_{i}\right) /(1+\bar{\lambda})}{\gamma \varepsilon_{i}}, \quad i=a, b, \\
& \frac{t_{i 1}^{*}-\theta_{i} \bar{t}_{i}^{*}}{1-t_{i 1}^{*}}=\frac{\gamma-\left(1+\lambda_{i}\right) /(1+\bar{\lambda})}{\gamma \varepsilon_{i}}, \quad i=a, b,
\end{aligned}
$$


where, as described in the article, it is:

$$
t_{i 1}^{*} \geq t_{i 2}^{*}, \quad \frac{\partial t_{i 1}^{*}}{\partial \theta_{i}}>\frac{\partial \bar{t}_{i}^{*}}{\partial \theta_{i}}>\frac{\partial t_{i 2}^{*}}{\partial \theta_{i}}=0 .
$$

\section{A.1 Lobbying only at the local level}

As a function of the equalization rates, per capita social welfare in type- 1 and type- 2 jurisdictions is defined in Eqs. (31)-(32) of the article. The derivatives with respect to $\theta_{i}$ are equal to:

$$
\begin{aligned}
\frac{\partial W_{1}^{*}}{\partial \theta_{i}} & =-\bar{z}_{i 1}^{*} \frac{\partial t_{i 1}^{*}}{\partial \theta_{i}}+\gamma \frac{\partial T_{1}^{*}}{\partial \theta_{i}}+\left(\gamma-\xi \delta_{1}\right) \frac{\partial E_{1}^{*}}{\partial \theta_{i}}, \\
\frac{\partial W_{2}^{*}}{\partial \theta_{i}} & =-\xi \delta_{2} \frac{\partial E_{1}^{*}}{\partial \theta_{i}} .
\end{aligned}
$$

Given that:

$$
T_{j}^{*}\left(\mathbf{t}_{j}^{*}\right)=\sum_{k \in\{a, b\}} t_{k j}^{*} \bar{z}_{k j}^{*}, \quad E_{1}^{*}\left(\mathbf{t}_{1}^{*}\right)=\sum_{k \in\{a, b\}} \theta_{k} \bar{t}_{k}^{*}\left(\bar{z}_{k}^{*}-\bar{z}_{k 1}^{*}\right),
$$

it is:

$$
\begin{aligned}
& \frac{\partial T_{1}^{*}}{\partial \theta_{i}}=\left(\bar{z}_{i 1}^{*}+t_{i 1}^{*} \frac{\partial \bar{z}_{i 1}^{*}}{\partial t_{i 1}}\right) \frac{\partial t_{i 1}^{*}}{\partial \theta_{i}}=\bar{z}_{i 1}^{*}\left(1-\frac{t_{i 1}^{*} \varepsilon_{i}}{1-t_{i 1}^{*}}\right) \frac{\partial t_{i 1}^{*}}{\partial \theta_{i}}, \\
& \frac{\partial T_{2}^{*}}{\partial \theta_{i}}=0 \\
& \frac{\partial E_{1}^{*}}{\partial \theta_{i}}=\bar{t}_{i}^{*}\left(\bar{z}_{i}^{*}-\bar{z}_{i 1}^{*}\right)+\theta_{i}\left(\bar{z}_{i}^{*}-\bar{z}_{i 1}^{*}\right) \frac{\partial \bar{t}_{i}^{*}}{\partial t_{i 1}} \frac{\partial t_{i 1}^{*}}{\partial \theta_{i}}+\frac{\bar{z}_{i 1}^{*}}{2} \frac{\theta_{i} \bar{t}_{i}^{*} \varepsilon_{i}}{1-t_{i 1}^{*}} \frac{\partial t_{i 1}^{*}}{\partial \theta_{i}} .
\end{aligned}
$$

Using the latter derivatives to compute the derivative of the social welfare function, $\Psi=W_{1}^{*}+(1-\psi) W_{2}^{*}$ :

$$
\frac{\partial \Psi}{\partial \theta_{i}}=\frac{\partial W_{1}^{*}}{\partial \theta_{i}}+(1-\psi) \frac{\partial W_{2}^{*}}{\partial \theta_{i}},
$$

after some manipulations we obtain the following derivative, which is the equivalent, for vertical equalization, of derivative (26) in the article for horizontal equalization:

$$
\begin{aligned}
\frac{\partial \Psi}{\partial \theta_{i}}=\left(\gamma-\xi+\psi \xi \delta_{2}\right)\left(\bar{z}_{i}^{*}-\bar{z}_{i 1}^{*}\right)\left\{\bar{t}_{i}^{*}+\theta_{i} \frac{\partial \bar{t}_{i}^{*}}{\partial t_{i 1}} \frac{\partial t_{i 1}^{*}}{\partial \theta_{i}}\right\}+ \\
+\frac{\lambda_{i}-\bar{\lambda}}{1+\bar{\lambda}} \bar{z}_{i 1}^{*} \frac{\partial t_{i 1}^{*}}{\partial \theta_{i}}-\left(\gamma+\left(1-\psi \delta_{2}\right) \xi\right) \frac{\bar{z}_{i 1}^{*}}{2} \frac{\theta_{i} \bar{t}_{i}^{*} \varepsilon_{i}}{1-t_{i 1}^{*}} \frac{\partial t_{i 1}^{*}}{\partial \theta_{i}}
\end{aligned}
$$

The first term of the derivative refers to equity, i.e., to the transfer of central tax revenues to type- 1 localities. If the central planner is concerned only about efficiency, and thus assigns equal weight to type- 1 and type- 2 jurisdictions in the social welfare function (i.e., $\psi=0$ ), then the equalization program financed by central taxation is 


\begin{tabular}{ccccccc|cccccc|ccc}
\hline Model & $p_{a 1}$ & $p_{a 2}$ & $p_{b 1}$ & $p_{b 2}$ & $\varepsilon_{a}$ & $\varepsilon_{b}$ & $\theta_{a}^{*}$ & $\theta_{b}^{*}$ & $t_{a 1}^{*}$ & $t_{a 2}^{*}$ & $t_{b 1}^{*}$ & $t_{b 2}^{*}$ & $W_{1}^{*}$ & $W_{2}^{*}$ & $W^{*}$ \\
\hline I.0 & 1.00 & 1.25 & 1.00 & 1.25 & 0.4 & 0.4 & - & - & .37 & .37 & .37 & .37 & 1.407 & 1.556 & 2.962 \\
& & & & & & .55 & .55 & .51 & .37 & .51 & .37 & 1.411 & 1.532 & 2.944 \\
\hline II.0 & 1.00 & 1.30 & 1.00 & 1.22 & 0.2 & 0.6 & - & - & .54 & .54 & .28 & .28 & 1.464 & 1.634 & 3.098 \\
& & & & & & .61 & .52 & .71 & .54 & .40 & .28 & 1.471 & 1.602 & 3.073 \\
\hline III.0 & 1.00 & 1.25 & 1.00 & 1.50 & 0.4 & 0.4 & - & - & .37 & .37 & .37 & .37 & 1.407 & 1.636 & 3.043 \\
&
\end{tabular}

Table A.1: Optimal vertical equalization in the absence of lobbying.

justified only if $\gamma>\xi$; that is, if the marginal benefits of local public expenditure exceed the social costs of the vertical transfer. If, instead, the social planner has some concern for equity (i.e., if $\psi>0$ ), then transfers can be justified even if $\gamma<\xi$. The second term in Eq. (A.4) shows how the equalization rates should be adjusted to counteract the distortions caused by lobbying. This term is positive for the strong lobby group $b$ (since $\lambda_{b}>\bar{\lambda}$ ) and negative for the weak group $a$ (since $\lambda_{a}<\bar{\lambda}$ ): as with horizontal equalization, it is good for efficiency to use the incentive effects of fiscal equalization to raise taxation on the strong lobby group and to decrease it on the weak one. The third term of the derivative refers to the total marginal cost of public funds of the resources used to finance the transfers (the higher the costs, the lower the equalization rate at the optimum).

For the same model specifications used in the article, Table A.1 shows optimal equalization of vertical type in the absence of lobbying. Note that the optimal equalization rates are generally higher under vertical than under horizontal equalization. The reason is that vertical equalization is less distortionary than horizontal equalization on local tax setting, since with the former only the recipient localities are induced to raise upwards their tax rates, while with the latter also the donor localities are distorted.

The comparison of Table A.2 with Table 2 in the article shows instead that lobbying at the local level impacts in a similar way on the optimal structure of the two types of equalization schemes. As groups $a$ and $b$ become more heterogeneous in terms of lobbying power, the optimal equalization rate increases for the tax base backed by the more powerful group $b$ and it lowers for that backed by the less powerful group $a$.

\section{A.2 Lobbying also at the central level}

When taxpayers lobby also the central policy maker on the equalization rates, the truthful contribution function of type- $i$ agents resident in a type- $j$ locality is defined 


\begin{tabular}{|c|c|c|c|c|c|c|c|c|c|c|c|}
\hline Model & $\lambda_{a}$ & $\lambda_{b}$ & $\theta_{a}^{*}$ & $\theta_{b}^{*}$ & $t_{a 1}^{*}$ & $t_{a 2}^{*}$ & $t_{b 1}^{*}$ & $t_{b 2}^{*}$ & $W_{1}^{*}$ & $W_{2}^{*}$ & $W^{*}$ \\
\hline \multirow[t]{2}{*}{ I.0 } & 0.2 & 0.2 & - & - & .37 & .37 & .37 & .37 & 1.407 & 1.556 & 2.962 \\
\hline & & & .55 & .55 & .51 & .37 & .51 & .37 & 1.411 & 1.532 & 2.944 \\
\hline \multirow[t]{2}{*}{ I. 1} & 0.2 & 0.4 & - & - & .42 & .42 & .30 & .30 & 1.405 & 1.554 & 2.959 \\
\hline & & & .29 & .83 & .50 & .42 & .52 & .30 & 1.412 & 1.530 & 2.942 \\
\hline \multirow[t]{2}{*}{ I. 2} & 0.2 & 0.6 & - & - & .46 & .46 & .23 & .23 & 1.403 & 1.551 & 2.953 \\
\hline & & & .09 & 1.00 & .48 & .46 & .48 & .23 & 1.413 & 1.529 & 2.942 \\
\hline \multirow[t]{2}{*}{ I. 3} & 0.2 & 1.0 & - & - & .51 & .51 & .09 & .09 & 1.394 & 1.538 & 2.932 \\
\hline & & & .00 & 1.00 & .51 & .51 & .21 & .08 & 1.404 & 1.530 & 2.934 \\
\hline 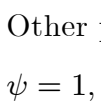 & & & & & & & & & & 5 & $=0.4$ \\
\hline
\end{tabular}

Table A.2: Optimal vertical equalization with lobbying at the local level.

as:

$$
Q_{i j}^{*}(\boldsymbol{\theta})=\lambda_{i} n_{i} w_{i j}\left(\mathbf{t}^{*}(\boldsymbol{\theta})\right)
$$

where welfare $w_{i j}($.$) is defined in Eqs. (A.1)-(A.2). In the aggregate:$

$$
Q^{*}(\boldsymbol{\theta})=\sum_{j=1}^{2} \sum_{i \in\{a, b\}} Q_{i j}^{*}(\boldsymbol{\theta})=\sum_{j=1}^{2} Q_{j}^{*}(\boldsymbol{\theta}) .
$$

Given that:

$$
\begin{aligned}
\frac{\partial Q_{1}^{*}}{\partial \theta_{i}} & =-\lambda_{i} \bar{z}_{i 1}^{*} \frac{\partial t_{i 1}^{*}}{\partial \theta_{i}}+\bar{\lambda} \gamma \frac{\partial T_{1}^{*}}{\partial \theta_{i}}+\bar{\lambda}\left(\gamma-\xi \delta_{1}\right) \frac{\partial E_{1}^{*}}{\partial \theta_{i}}, \\
\frac{\partial Q_{2}^{*}}{\partial \theta_{i}} & =-\bar{\lambda} \xi \delta_{2} \frac{\partial E_{1}^{*}}{\partial \theta_{i}}
\end{aligned}
$$

after some manipulations we get the following derivative, which is the equivalent of derivative (30) in the article for horizontal equalization:

$$
\begin{aligned}
\sum_{j=1}^{2} \frac{\partial Q_{j}^{*}}{\partial \theta_{i}}=\bar{\lambda}(\gamma-\xi)\left(\bar{z}_{i}^{*}-\bar{z}_{i 1}^{*}\right) & \left\{\bar{t}_{i}^{*}+\theta_{i} \frac{\partial \bar{t}_{i}^{*}}{\partial t_{i 1}} \frac{\partial t_{i 1}^{*}}{\partial \theta_{i}}\right\}+ \\
& -\frac{\lambda_{i}-\bar{\lambda}}{1+\bar{\lambda}} \bar{z}_{i 1}^{*} \frac{\partial t_{i 1}^{*}}{\partial \theta_{i}}-\bar{\lambda}(\gamma+\xi) \frac{\bar{z}_{i 1}^{*}}{2} \frac{\theta_{i} \bar{t}_{i}^{*} \varepsilon_{i}}{1-t_{i 1}^{*}} \frac{\partial t_{i 1}^{*}}{\partial \theta_{i}} .
\end{aligned}
$$

The derivative in Eq. (A.5) shows how lobbying at the central level can distort the choice of the equalization rates, whose optimal determination is governed by the derivative of social welfare given in Eq. (A.4). Note first that the second term in derivative (A.5) cancels out with the corresponding term in derivative (A.4). This 


\begin{tabular}{|c|c|c|c|c|c|c|c|c|c|c|c|c|}
\hline Model & $\lambda_{a}$ & $\lambda_{b}$ & Lobbying & $\theta_{a}^{*}$ & $\theta_{b}^{*}$ & $t_{a 1}^{*}$ & $t_{a 2}^{*}$ & $t_{b 1}^{*}$ & $t_{b 2}^{*}$ & $W_{1}^{*}$ & $W_{2}^{*}$ & $W^{*}$ \\
\hline \multirow[t]{2}{*}{ I.0 } & 0.2 & 0.2 & only local & .55 & .55 & .51 & .37 & .51 & .37 & 1.411 & 1.532 & 2.944 \\
\hline & & & local and central & .34 & .34 & .45 & .37 & .45 & .37 & 1.410 & 1.543 & 2.953 \\
\hline \multirow[t]{2}{*}{ I.1 } & 0.2 & 0.4 & only local & .29 & .83 & .50 & .42 & .52 & .30 & 1.412 & 1.530 & 2.942 \\
\hline & & & local and central & .24 & .32 & .48 & .42 & .37 & .30 & 1.409 & 1.545 & 2.954 \\
\hline \multirow[t]{2}{*}{ I.2 } & 0.2 & 0.6 & only local & .09 & 1.00 & .48 & .46 & .48 & .23 & 1.413 & 1.529 & 2.942 \\
\hline & & & local and central & .17 & .32 & .50 & .46 & .29 & .23 & 1.406 & 1.543 & 2.950 \\
\hline \multirow[t]{2}{*}{ I.3 } & 0.2 & 1.0 & only local & .00 & 1.00 & .51 & .51 & .21 & .08 & 1.404 & 1.530 & 2.934 \\
\hline & & & local and central & .08 & .43 & .54 & .51 & .13 & .09 & 1.397 & 1.534 & 2.931 \\
\hline
\end{tabular}

Other parameters as in Table A.2.

Table A.3: Vertical equalization with lobbying at the local and central level.

means that with lobbying at the central level there are no distortions of the equalization rates due to heterogeneity in lobbying power, as measured by the difference $\lambda_{i}-\bar{\lambda}$, but only distortions due to the average power of the lobby groups, as measured by the parameter $\bar{\lambda}$. That is, lobbying at the central level distorts the choices of the central policy maker towards a less egalitarian, hence more efficiency oriented, equalization policy.

The comparison of Table A.3 with Table 3 in the article shows that lobbying at the local and at the central level impact in a similar way on the structure of the two types of equalization schemes. If groups $a$ and $b$ are similar in terms of lobbying power, then lobbying at the central level distorts downward both equalization rates. If, instead, the two groups are highly heterogeneous in terms of lobbying power, then the central government is induced to distort upward the equalization rate on the less powerful group, downward on the more powerful one. When lobbying at the central level is highly distortionary, uniform equalization may then perform better than differential equalization also with a vertical scheme, as shown in the article for horizontal equalization.

\section{B. Mobility of production factors}

We now generalize our model by allowing for mobility of production factors. In particular, we continue to assume that the place of residence is fixed for all agents. However, agents now have the option to commute to another locality to supply their production factor and earn their income. Local income taxes are applied on a residence basis, an 
arrangement widely employed at sub-national levels of government. ${ }^{1}$ Also, we examine only the case of horizontal equalization.

We consider imperfect mobility by assuming that an agent supplying her production factor in a 'foreign' locality sustains a lump sum cost $\mu$, with $\mu$ distributed within the group of type- $i$ agents according to the density function $f_{i}(\mu) \geq 0$ on the support $\mu=[0,+\infty)$, with cumulative distribution denoted by $F_{i}(\mu)$. The cost $\mu$ can be interpreted as the per period monetary (e.g., travel expenses) and non-monetary (e.g., time spent travelling) costs of commuting.

Under residence taxation, no agent has incentives to commute to a foreign locality of the same type, since commuting implies mobility costs but no income gain. It is also never profitable to commute from a rich to a poor locality. Mobility can instead be profitable for agents resident in type-1, poor, localities, since by commuting to a type-2, rich, locality they can take home higher net earnings. Therefore, in the present setting, mobility occurs only from poor to rich localities.

In order to focus on symmetric equilibria under agents' mobility, we assume that each type-1 locality is 'connected' with only one type-2 locality, and viceversa (recall that there is an identical and large number $J>1$ of localities of each type). Hence, the agents who are resident in a given type-1 locality have the opportunity to supply their own production factor either at 'home' or 'abroad', in another, and only one, type-2 locality.

Consider a type- $(i, \mu)$ agent who is resident in a type- 1 locality: 1 denotes the 'home-poor' locality and 2 the connected 'foreign-rich' locality. The agent chooses to supply at home if $v_{i 1}\left(t_{i 1}\right) \geq \hat{v}_{i 2}\left(t_{i 1}\right)-\mu$, and abroad otherwise, where $v_{i j}$ is the indirect utility function defined in Eq. (5) of the article,

$$
\begin{aligned}
& v_{i 1}\left(t_{i 1}\right)=\left(1-t_{i 1}\right) p_{i 1} \tilde{x}_{i 1}\left(p_{i 1}, t_{i 1}\right)+\phi^{i}\left(1-\tilde{x}_{i 1}\left(p_{i 1}, t_{i 1}\right)\right), \\
& \hat{v}_{i 2}\left(t_{i 1}\right)=\left(1-t_{i 1}\right) p_{i 2} \hat{x}_{i 2}\left(p_{i 2}, t_{i 1}\right)+\phi^{i}\left(1-\hat{x}_{i 2}\left(p_{i 2}, t_{i 1}\right)\right),
\end{aligned}
$$

and where $\hat{x}_{i 2}$ is the supply in a type- 2 locality of a type- $i$ agent resident in a type1 locality (a commuter), while $\tilde{x}_{i 1}$ is the supply at home. Since, by Assumption 1, $p_{i 1}<p_{i 2}$, and supply is upward sloping, it is $\tilde{x}_{i 1}<\hat{x}_{i 2}$ : supply is higher abroad than at home, because productivity abroad is higher than at home. Hence, $\hat{v}_{i 2}>v_{i 1}$, $p_{i 2} \hat{x}_{i 2}>p_{i 1} \tilde{x}_{i 1}$.

Note that the choice of whether to supply at home or abroad is made by comparing only the private components, $v_{i 1}$ and $\hat{v}_{i 2}$, of individual welfare. That is, we are

\footnotetext{
${ }^{1}$ In Italy, for instance, the regional and the municipal surcharge tax on the personal income tax is applied on a residence basis. See the working paper version of this paper (Esteller-Moré et al., 2015), for an analysis of production factors mobility under taxation at source.
} 
assuming that commuters enjoy only the public goods provided at home, in their place of residence, while they do not consume those provided abroad, where they earn their income.

The mass of type- $i$ agents resident in a poor locality and commuting to a rich locality is equal to:

$$
m_{i 1}\left(t_{i 1}\right)=n_{i} F_{i}\left(\hat{v}_{i 2}-v_{i 1}\right)>0,
$$

while that of those supplying at home is equal to $n_{i}-m_{i 1}\left(t_{i 1}\right)$.

If taxation in a poor locality is increased, the number of commuters declines, since:

$$
\frac{\partial m_{i 1}}{\partial t_{i 1}}=-n_{i} f_{i}\left(\hat{v}_{i 2}-v_{i 1}\right)\left(p_{i 2} \hat{x}_{i 2}-p_{i 1} \tilde{x}_{i 1}\right)<0
$$

The reason is that an increase in taxation affects more severely welfare of commuters than that of non-commuters:

$$
\frac{\partial \hat{v}_{i 2}}{\partial t_{i 1}}=-p_{i 2} \hat{x}_{i 2}<-p_{i 1} \tilde{x}_{i 1}=\frac{\partial v_{i 1}}{\partial t_{i 1}}<0 .
$$

Because of factors' mobility, Eq. (7) in the article, defining the per capita tax base of production factor $k$ in a type-1 jurisdiction, is modified as follows:

$$
\bar{z}_{k 1}=n_{k} p_{k 1} \tilde{x}_{k 1}+m_{k 1}\left(p_{k 2} \hat{x}_{k 2}-p_{k 1} \tilde{x}_{k 1}\right)
$$

The first term in Eq. (B.2) is income, or tax base, in the absence of mobility; the second term represents the extra income earned by commuters that supply in the more productive type- 2 locality. The per capita tax base of production factor $k$ in a type- 2 jurisdiction is the same as in Eq. (7) of the article, since there are no commuters from type- 2 to type- 1 localities.

An increase in taxation in a type-1 locality affects its tax base on production factor $k$ as follows:

$$
\frac{\partial \bar{z}_{k 1}}{\partial t_{k 1}}=-\frac{\bar{z}_{k 1} \varepsilon_{k}}{1-t_{k 1}}+\left(p_{k 2} \hat{x}_{k 2}-p_{k 1} \tilde{x}_{k 1}\right) \frac{\partial m_{k 1}}{\partial t_{k 1}} .
$$

The first term is the behavioral effect due to the elasticity of production factor's supply. The second term is the behavioral effect due to the reduction in the number of commuters.

\section{B.1 Equilibrium tax rates}

The determination of tax policy by local governments is unaffected by factors' mobility for type-2 localities, since none of its residents commutes. Hence, we focus on the determination of tax policy in type- 1 localities. 
Using Eq. (B.5), for a type-1 locality, an increase in its own tax rate $t_{i 1}$ impacts on tax tax revenues and equalization grants as follows (recall that each locality takes as given the average tax rate and tax base at the national level):

$$
\frac{\partial T_{1}}{\partial t_{i 1}}+\frac{\partial E_{1}}{\partial t_{i 1}}=\bar{z}_{i 1}\left(1-\left(t_{i 1}-\theta_{i} \bar{t}_{i}\right)\left(\frac{\varepsilon_{i}}{1-t_{i 1}}-\frac{\eta_{i}\left(t_{i 1}\right)}{m_{i 1}} \frac{\partial m_{i 1}}{\partial t_{i 1}}\right)\right),
$$

where

$$
\eta_{i}\left(t_{i 1}\right)=\frac{m_{i 1}\left(p_{i 2} \hat{x}_{i 2}-p_{i 1} \tilde{x}_{i 1}\right)}{\bar{z}_{i 1}}
$$

represents the incidence on total income $\bar{z}_{i 1}$ of the extra income that type- $i$ agents resident in a type- 1 locality earn by commuting in a type-2 locality.

Type- $(i, \mu)$ agents resident in a type- 1 locality are divided into two groups: that of those supplying at home, with commuting cost $\mu \geq \hat{v}_{k 2}-v_{k 1}$, of mass $n_{i}-m_{i 1}$, with welfare:

$$
w_{i 1}\left(\mathbf{t}_{1}\right)=v_{i 1}\left(t_{i 1}\right)+\gamma\left[T_{1}\left(\mathbf{t}_{1}\right)+E_{1}\left(\mathbf{t}_{1}\right)\right],
$$

and that of those supplying abroad, $\mu<\hat{v}_{k 2}-v_{k 1}$, of mass $m_{i 1}$, with welfare:

$$
\hat{w}_{i 1}\left(\mathbf{t}_{1}\right)=\hat{v}_{i 2}\left(t_{i 1}\right)-\mu+\gamma\left[T_{1}\left(\mathbf{t}_{1}\right)+E_{1}\left(\mathbf{t}_{1}\right)\right] .
$$

Per capita social welfare in a type-1 locality is thus equal to:

$$
W_{1}\left(\mathbf{t}_{1}\right)=\sum_{k \in\{a, b\}} n_{k}\left(\int_{0}^{\hat{v}_{k 2}-v_{k 1}}\left(\hat{v}_{k 2}-\mu\right) \mathrm{d} F_{k}+\int_{\hat{v}_{k 2}-v_{k 1}}^{\infty} v_{k 1} \mathrm{~d} F_{k}+\gamma\left(T_{1}+E_{1}\right)\right) .
$$

We assume that only the resident agents lobby their own local policy maker. In fact, residents in a type-1 locality commuting to a type-2 locality have no incentives to lobby the policy maker abroad, since their income earned abroad is taxed at home and public goods are enjoyed at home. Under the influence of lobbying, the objective function of the local policy maker of a type-1 locality is equal to:

$$
\Omega_{1}\left(\mathbf{t}_{1}\right)=\sum_{k \in\{a, b\}}\left(1+\lambda_{k}\right) n_{k}\left(\int_{0}^{\hat{v}_{k 2}-v_{k 1}}\left(\hat{v}_{k 2}-\mu\right) \mathrm{d} F_{k}+\int_{\hat{v}_{k 2}-v_{k 1}}^{\infty} v_{k 1} \mathrm{~d} F_{k}+\gamma\left(T_{1}+E_{1}\right)\right) .
$$

The first order condition for maximizing Eq. (B.7) with respect to tax rate $t_{i 1}$ is equal to:

$$
\frac{\partial \Omega_{1}}{\partial t_{i 1}}=\left(1+\lambda_{i}\right) n_{i}\left(\int_{0}^{\hat{v}_{k 2}-v_{k 1}} \frac{\partial \hat{v}_{i 2}}{\partial t_{i 1}} \mathrm{~d} F_{k}+\int_{\hat{v}_{k 2}-v_{k 1}}^{\infty} \frac{\partial v_{i 1}}{\partial t_{i 1}} \mathrm{~d} F_{k}\right)+(1+\bar{\lambda}) \gamma\left(\frac{\partial T_{1}}{\partial t_{i 1}}+\frac{\partial E_{1}}{\partial t_{i 1}}\right)=0 .
$$


Using Eqs. (B.3) and (B.4), Eq. (B.8) can be written as:

$$
\frac{\partial \Omega_{1}}{\partial t_{i 1}}=-\left(1+\lambda_{i}\right) \bar{z}_{i 1}+(1+\bar{\lambda}) \gamma\left(\frac{\partial T_{1}}{\partial t_{i 1}}+\frac{\partial E_{1}}{\partial t_{i 1}}\right)=0 .
$$

Finally, using Eq. (B.6), the condition characterizing the choice of tax rate $t_{i 1}$ by a type-1 locality is given by:

$$
\frac{t_{i 1}-\theta_{i} \bar{t}_{i}}{1-t_{i 1}}=\frac{\gamma-\left(1+\lambda_{i}\right) /(1+\bar{\lambda})}{\gamma\left(\varepsilon_{i}-\frac{\left(1-t_{i 1}\right) \eta_{i}\left(t_{i 1}\right)}{m_{i 1}} \frac{\partial m_{i 1}}{\partial t_{i 1}}\right)} .
$$

The corresponding condition for a type-2 locality is equal to that reported in the article at Eq. (18), that is:

$$
\frac{t_{i 2}-\theta_{i} \bar{t}_{i}}{1-t_{i 2}}=\frac{\gamma-\left(1+\lambda_{i}\right) /(1+\bar{\lambda})}{\gamma \varepsilon_{i}} .
$$

Eqs. (B.9)-(B.10) simultaneously define the equilibrium tax rates $\left(t_{i 1}^{*}, t_{i 2}^{*}\right)$ on tax base $i$. Note that, while in the absence of mobility it is $t_{i 1}^{*}=t_{i 2}^{*}$, since the right hand sides of Eqs. (B.9)-(B.10) are identical, in the presence of commuters from type-1 to type-2 localities it is $t_{i 1}^{*}<t_{i 2}^{*}$. The reason is simple. When a type-1, poor, locality, increases taxation, some of its residents decide to drop commuting to a type- 2 rich locality. Hence, because of mobility, the tax base of a type-1 locality is more elastic than the corresponding tax base of a type-2 locality. The elasticity due to mobility is seen in Eq. (B.9) as the second term in the denominator of the right hand side of the equation.

\section{B.2 Fiscal equalization under tax base mobility}

We do not formally derive, as in the article, the first order conditions for the optimal equalization rates in the presence of lobbying at the local level, neither those for the equilibrium equalization rates with lobbying at both levels of government. We only replicate the numerical simulations presented in the article with the added feature of tax base mobility.

By comparing Table B.1 with Table 1 in the article, we see that factors' mobility reduces the optimal equalization rates from above to below $50 \%$ in all model specifications. With factors' mobility there is less need for inter-regional redistribution, since people commuting from poor to rich localities (in the simulations, about $20-30 \%$ of the residents commute) determine a reduction in the income gap between poor and rich 


\begin{tabular}{ccccccc|cccccc|cccccc}
\hline Model & $p_{a 1}$ & $p_{a 2}$ & $p_{b 1}$ & $p_{b 2}$ & $\varepsilon_{a}$ & $\varepsilon_{b}$ & $\theta_{a}^{*}$ & $\theta_{b}^{*}$ & $t_{a 1}^{*}$ & $t_{a 2}^{*}$ & $t_{b 1}^{*}$ & $t_{b 2}^{*}$ & $W_{1}^{*}$ & $W_{2}^{*}$ & $W^{*}$ & $m_{a 1}^{*}$ & $m_{b 1}^{*}$ \\
\hline I.0 & 1.00 & 1.25 & 1.00 & 1.25 & 0.4 & 0.4 & - & - & .30 & .37 & .30 & .37 & 1.435 & 1.556 & 2.991 & .14 & .14 \\
& & & & & & & .40 & .40 & .44 & .48 & .44 & .48 & 1.441 & 1.537 & 2.978 & .10 & .10 \\
\hline II.0 & 1.00 & 1.30 & 1.00 & 1.22 & 0.2 & 0.6 & - & - & .39 & .54 & .25 & .28 & 1.504 & 1.634 & 3.138 & .20 & .09 \\
& & & & & & & .39 & .41 & .56 & .65 & .37 & .39 & 1.510 & 1.614 & 3.124 & .14 & .07 \\
\hline III.0 & 1.00 & 1.25 & 1.00 & 1.50 & 0.4 & 0.4 & - & - & .30 & .37 & .21 & .37 & 1.487 & 1.636 & 3.124 & .14 & .34 \\
& & & & & & & .40 & .19 & .44 & .48 & .26 & .41 & 1.491 & 1.625 & 3.116 & .10 & .31 \\
\hline
\end{tabular}

Other parameters: $\lambda_{a}=\lambda_{b}=0, \psi=1, n_{a}=n_{b}=.5, \gamma=1.3, \mu$ uniform on $[0,0.3]$.

Table B.1: Optimal equalization in the absence of lobbying (mobility).

\begin{tabular}{ccc|cccccc|ccc|cc}
\hline Model & $\lambda_{a}$ & $\lambda_{b}$ & $\theta_{a}^{*}$ & $\theta_{b}^{*}$ & $t_{a 1}^{*}$ & $t_{a 2}^{*}$ & $t_{b 1}^{*}$ & $t_{b 2}^{*}$ & $W_{1}^{*}$ & $W_{2}^{*}$ & $W^{*}$ & $m_{a 1}^{*}$ & $m_{b 1}^{*}$ \\
\hline $\mathbf{I . 0}$ & 0.2 & 0.2 & - & - & .30 & .37 & .30 & .37 & 1.435 & 1.556 & 2.991 & .14 & .14 \\
& & & .40 & .40 & .44 & .48 & .44 & .48 & 1.441 & 1.537 & 2.978 & .10 & .10 \\
\hline $\mathbf{I . 1}$ & 0.2 & 0.4 & - & - & .36 & .42 & .24 & .30 & 1.434 & 1.554 & 2.988 & .12 & .16 \\
& & & .26 & .54 & .45 & .49 & .44 & .47 & 1.441 & 1.537 & 2.978 & .10 & .10 \\
\hline $\mathbf{I . 2}$ & 0.2 & 0.6 & - & - & .40 & .46 & .18 & .23 & 1.431 & 1.551 & 2.982 & .11 & .17 \\
& & & .15 & .66 & .45 & .50 & .43 & .46 & 1.442 & 1.537 & 2.978 & .10 & .10 \\
\hline \multirow{2}{*}{$\mathbf{I . 3}$} & 0.2 & 1.0 & - & - & .46 & .51 & .06 & .09 & 1.422 & 1.538 & 2.960 & .10 & .21 \\
& & & .00 & .88 & .46 & .51 & .42 & .43 & 1.443 & 1.535 & 2.978 & .10 & .10 \\
\hline
\end{tabular}

Other parameters: $p_{a 1}=p_{b 1}=1.00, p_{a 2}=p_{b 2}=1.25, \varepsilon_{a}=\varepsilon_{b}=0.4$,

$\psi=1, n_{a}=n_{b}=.5, \gamma=1.3, \mu$ uniform on $[0,0.3]$.

Table B.2: Optimal equalization with lobbying at the local level (mobility). 


\begin{tabular}{|c|c|c|c|c|c|c|c|c|c|c|c|c|c|c|}
\hline Model & $\lambda_{a}$ & $\lambda_{b}$ & Lobbying & $\theta_{a}^{*}$ & $\theta_{b}^{*}$ & $t_{a 1}^{*}$ & $t_{a 2}^{*}$ & $t_{b 1}^{*}$ & $t_{b 2}^{*}$ & $W_{1}^{*}$ & $W_{2}^{*}$ & $W^{*}$ & $m_{a 1}^{*}$ & $m_{b 1}^{*}$ \\
\hline \multirow[t]{2}{*}{ I.0 } & 0.2 & 0.2 & only local & .40 & .40 & .44 & .48 & .44 & .48 & 1.441 & 1.537 & 2.978 & .10 & .10 \\
\hline & & & local and central & .31 & .31 & .40 & .45 & .40 & .45 & 1.440 & 1.544 & 2.984 & .11 & .11 \\
\hline \multirow[t]{2}{*}{ I. 1} & 0.2 & 0.4 & only local & .26 & .54 & .45 & .49 & .44 & .47 & 1.441 & 1.537 & 2.978 & .10 & .10 \\
\hline & & & local and central & .33 & .18 & .47 & .51 & .28 & .34 & 1.437 & 1.543 & 2.981 & .09 & .14 \\
\hline \multirow[t]{2}{*}{ I. 2} & 0.2 & 0.6 & only local & .15 & .66 & .45 & .50 & .43 & .46 & 1.442 & 1.537 & 2.978 & .10 & .10 \\
\hline & & & local and centra 1 & .33 & .00 & .52 & .55 & .18 & .23 & 1.431 & 1.538 & 2.969 & .08 & .17 \\
\hline \multirow[t]{2}{*}{ I. 3} & 0.2 & 1.0 & only local & .00 & .88 & .46 & .51 & .42 & .43 & 1.443 & 1.535 & 2.978 & .10 & .10 \\
\hline & & & local and central & .31 & .00 & .57 & .60 & .06 & .09 & 1.420 & 1.524 & 2.943 & .07 & .21 \\
\hline
\end{tabular}

Other parameters as in Table B.2.

Table B.3: Equalization with lobbying at the local and central level (mobility).

localities. Fiscal equalization, by reducing the average income gaps between poor and rich localities, discourages commuting.

The comparison of Table B.2 with Table 2 in the article shows that lobbying at the local level impacts in a similar way on the optimal structure of the equalization rates with and without tax base mobility. As groups $a$ and $b$ become more heterogeneous in terms of lobbying power, the optimal equalization rate increases for the tax base backed by the more powerful group $b$ and it lowers for that backed by the less powerful group $a$.

Finally, the comparison of Table B.3 with Table 3 in the article shows that lobbying at the local and at the central level impact in a similar way on the equilibrium structure of the equalization rates with and without tax base mobility. 